\title{
Non-Heteroatom-Substituted Alkylidene Complexes of Groups 10 and 11
}

\author{
Riccardo Peloso,* Ernesto Carmona
}

\author{
Instituto de Investigaciones Químicas (IIQ), Departamento de \\ Química Inorgánica and Centro de Innovación en Química Avanzada \\ (ORFEO-CINQA), Universidad de Sevilla and Consejo Superior de \\ Investigaciones Científicas (CSIC) \\ Avenida Américo Vespucio 49, 41092 Sevilla (Spain) \\ E-mails: rpeloso@us.es,guzman@us.es
}

\section{Keywords:}

carbenes; alkylidenes; organometallic chemistry; group 10 metals; group 11 metals.

\author{
Abbreviations: \\ Mes = 2,4,6-trimethylphenyl \\ $\mathrm{Xyl}=2,6$-dimethylphenyl \\ $p$-Tol = 4-methylphenyl \\ $\mathrm{Tf}=$ trifluoromethylsulphonyl \\ $\mathrm{EDA}=$ ethyl diazoacetate
}

\section{Highlights:}

- use of terms "carbene" and "alkylidene" in organometallic chemistry is discussed

- unusual species included are cationic Ni(III), Pd(II), Pt(IV) and $\mathrm{Ag}(\mathrm{I})$ alkylidenes

- group 10 and 11 alkylidene complexes with no heteroatom stabilization are reviewed

\section{Abstract.}

This review aims to offer a detailed summary of the discoveries regarding nonheteroatom-substituted alkylidenes of the groups 10 and 11 metals that have appeared in the literature since the first representative of this class was reported in 2002. Special attention is focused on synthetic and bonding aspects of well-defined species. The importance of this family of compounds in catalytic organic transformations is often 
mentioned and a number of references are provided. We stress, however, that it is not the main issue of this review, as this topic has received considerable attention in the current literature.

\section{Introduction and Scope.}

Transition metal complexes with carbene ligands have expanded over the years to constitute one of the most important families of organometallic compounds. Since the development of $\mathrm{N}$-heterocyclic carbenes $(\mathrm{NHCs})^{1}$, and more recently of the also highly versatile cyclic(alkyl)(amino)carbenes $(\mathrm{CAACs})^{2}$, carbenes have been employed as ancillary ligands to provide thermodynamic and kinetic stability to countless transition metal complexes and reaction intermediates. These carbenes have become indispensable partners of $d$ transition elements and main group metals alike, and perform an invaluable function in homogeneous catalysis. ${ }^{1,2}$

Notwithstanding the importance of carbenes as spectator ligands, the vital role that transition metal carbenes play in modern chemistry rests largely on the extraordinarily rich and diverse reactivity of the $\mathrm{M}=\mathrm{C}$ bond, that allows their successful applications in diverse organic transformations whose importance cannot be overstated, not least in homogeneous catalytic olefin metathesis. ${ }^{3-10}$

The explosive growth of the field has naturally given rise to extensive literature coverage. A comprehensive annual survey on the progress of metal-carbene chemistry is provided by Herndon in this Journal, with the latest, covering the year 2015, appearing in the second half of $2016 .{ }^{11}$ In this article we concentrate on carbenes of late transition metals. Complexes of $\mathrm{Fe}, \mathrm{Ru}$ and $\mathrm{Os}$ with carbene ligands have been known for several decades. Similarly, a variety of carbene complexes of Group 9 elements have attracted considerable attention. In particular, we and other researchers have described a number of complexes of $\operatorname{Ir}(\mathrm{III})$ with carbenes of both the :CRR' and :CRX types (X = heteroatom substituent). ${ }^{12-15}$ Accordingly, as detailed later, the aim of this review is to offer a concise summary of complexes of groups 10 and 11 metals with carbene ligands devoid of heteroatoms.

Before we discuss this chemistry in due detail, a word is perhaps necessary on the terminology we use in this review. The comments we will make in this regard will smoothly lead us to some, necessarily brief, considerations on the reactivity modes exhibited by the metal-carbene bond and on the bonding models supporting this chemistry. 
The terms "carbene" and "alkylidene" are often used as synonymous by coordination and organometallic chemists. Even though both indicate an organic fragment that binds to a metal centre through a divalent 6-electron carbon atom, $: C(R) R^{\prime}$, this causes confusion and creates ambiguity. The origin of the above terms is as follows.

In 1964, Fischer and Maasböl prepared the first transition metal carbene, ${ }^{16 a}$ the tungsten complex $\mathrm{W}(\mathrm{C}(\mathrm{OMe}) \mathrm{Me})(\mathrm{CO})_{5}$, that was soon followed by other related compounds. ${ }^{16 \mathrm{~b}, \mathrm{c}}$ These complexes are 18 -electron species in low oxidation states. They are reasonably stable and feature heteroatoms at the carbene atom, which generally exhibits electrophilic reactivity. Only four years later, Öfele reported a surprisingly stable chromium complex containing also a $\mathrm{Cr}(\mathrm{CO})_{5}$ fragment, but bound to a cyclopropylidene unit, i.e. a carbene ligand with no heteroatom. ${ }^{17}$ Subsequently, Schrock discovered a new class of metal carbenes, exemplified by the 10-electron species $\mathrm{Ta}\left(\mathrm{CHCMe}_{3}\right)\left(\mathrm{CH}_{2} \mathrm{CMe}_{3}\right)_{3}$. In the series of complexes made by Schrock and coworkers, ${ }^{18}$ an early transition metal in high oxidation state, with 10 to 16 valence electrons, is bonded to a nucleophilic carbene carrying $\mathrm{C}$ or $\mathrm{H}$ substituents at the carbon atom. It soon became customary to name the two classes of metal carbenes as Fischer and Schrock carbenes, respectively.

In the following years many compounds of general formula $L_{n} M=C R R$ ', where $\mathrm{R}$ and $\mathrm{R}$ ' are $\mathrm{H}$, alkyl or aryl, were prepared and named alkylidenes as derivatives of alkyls, ${ }^{19}$ regardless of their nucleophilic or electrophilic reactivity. In this way, it became common practice to use the term "alkylidene" when referring to complexes with $\mathrm{H}$, alkyl or aryl substituents on the carbon, and "carbene" to refer to species with one or two heteroatom substituents. ${ }^{20 a}$ But this was not uniformly accepted by researchers in the field. Many, utilized carbene and alkylidene for Fischer and Schrock complexes, respectively, whereas others employed only carbene, or only alkylidene, for all metal carbenes, or even used the two terms interchangeably. The nomenclature committee of the IUPAC recommended that carbene should be reserved for describing the free ligand, naming all transition metal complexes of carbenes as substituted alkylidenes. ${ }^{21}$ As it is evident nowadays, these recommendations have not been standard practice among transition metal carbene chemists. However in his recent book ${ }^{22 a}$ Bochmann states that the systematic term "alkylidenes" is now applied to all types of carbenes. Moreover, the expression alkylidene complexes in low oxidation states is employed as equivalent to 
Fischer carbenes, while alkylidene complexes in high oxidation states $\left(d^{o}\right)$ is meant to describe Schrock carbenes. ${ }^{22 a}$

The real distinction between the two families of carbene complexes resides doubtless in the nucleophilic or electrophilic reactivity they may display. ${ }^{22}$ As lucidly compiled and discussed by Roper some 30 years ago, ${ }^{20}$ similar to other chemical reactions, those of coordinated carbenes are influenced by frontier orbital-controlled and charge-controlled factors. ${ }^{23}$ Thus, despite the $\mathrm{M}^{\delta+}-\mathrm{C}^{\delta-}$ polarity of the metal-carbene bond that may be suggestive of nucleophilic behaviour, the reactions of Fischer carbenes (e.g. $\left.\mathrm{Cr}(=\mathrm{CXY})(\mathrm{CO})_{5}\right)$ with nucleophiles are frontier-orbital controlled. Hence, electron density transfer from the HOMO of the nucleophile to the carbene complex LUMO, that resides largely on $\mathrm{C}_{\alpha}$, disrupts the usually reduced $\pi$ interaction found in these complexes and converts the metal-carbene bond into a metal-alkyl one. Conversely, when the metal-carbene bond has high $\pi$ character as in Schrock carbenes, electrophilic attack at the carbene carbon atom is expected, particularly when this atom is most negatively charged and when the $\pi$ bonding orbital has strong carbon- $\mathrm{p}_{\pi}$ character. $^{20 \mathrm{~b}}$

An alternative interpretation of carbene reactivity based on quantum-mechanic calculations was offered by Hall in $1984 .{ }^{24}$ In this approach the electrophilic or nucleophilic reactivity of the $\mathrm{M}=\mathrm{C}$ bond can be explained with the aid of different bonding schemes (Figure 1). Using the isolobal analogy, 18-electron metal carbenes may be viewed as arising from the bonding of singlet metal and singlet carbene fragments, i.e. from donor-acceptor $\sigma$ and $\pi$ interactions (Figure 1a). ${ }^{20,22}$ Clearly, the resulting dative covalent bonds ${ }^{25}$ would be akin those in M-CO linkages, such that for the singlet-bonding, donor-acceptor metal carbene scheme, electrophilic reactivity can reasonably be expected. Moreover, singlet electronic states would be favoured by strong $\pi$ acceptors at the metal and by heteroatom substituents on the carbene, which increase the HOMO-LUMO gap in the carbene ligand. ${ }^{20}$

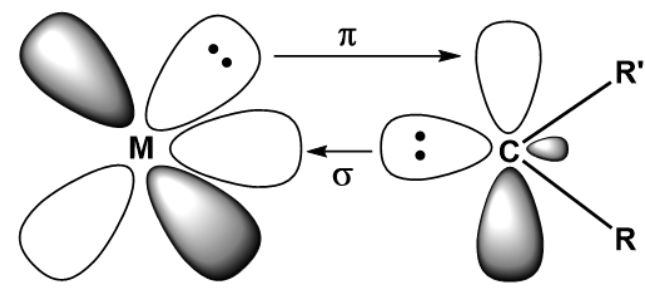

(a) Fischer type

$$
M \stackrel{\pi}{\stackrel{\leftrightarrow}{\rightleftarrows}} C_{\mid}^{\prime}
$$

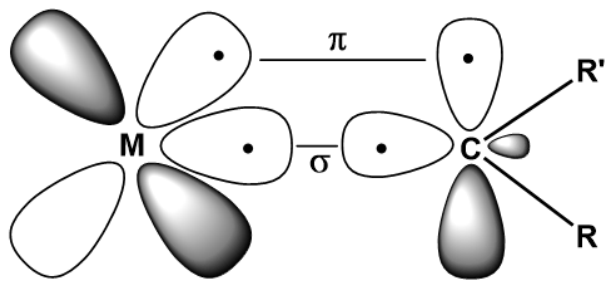

(b) Schrock type 
Figure 1. Bonding situations in metal complexes with carbene ligands. ${ }^{22}$ (a) Singlet metal and singlet carbene fragments proposed for low oxidation state Fischer carbenes. (b) The triplet metal and carbene building blocks in high oxidation state alkylidene complexes (Schrock carbenes).

In contrast, nucleophilic, often electron-deficient metal carbenes, can be electronically associated with triplet electronic states of their metal and carbene building units (Figure 1b), resulting in the formation of two normal covalent bonds, ${ }^{25}$ and in olefinic-like, i.e. nucleophilic reactivity of the $\mathrm{M}=\mathrm{C}$ bond. In this case, triplet states can be foreseen for metal fragments that lack strong $\pi$ acceptor ligands, as well as for carbenes bearing only hydrogen or hydrocarbyl substituents, particularly alkyl groups. Naturally, intermediate cases appear when a metal fragment of one type combines with a carbene ligand of the other. These "hybrids" of Fischer and Schrock complexes ${ }^{26}$ have been known since the early days of transition metal carbene chemistry and continue at present to enrich our knowledge of the field. ${ }^{27}$ Some early examples were calculated to have reduced bond strength, reflecting the cost in energy of promoting one fragment to an excited state of the correct multiplicity. ${ }^{20 a}$ In addition, and in good agreement with experimental observations, these considerations support the expectation of a wide range of reactivity modes for the metal-carbene bond, rather than a clear-cut differentiation between electrophilic and nucleophilic patterns.

To complete this brief lexical overview, it is worth mentioning that organic species formally bearing a positive charge and a carbon-metal bond at the same carbon atom are often called "carbenoids". 3a This definition is particularly useful for electrophilic late-transition alkylidene complexes for which Fürstner recommends to avoid the notation $[\mathrm{M}=\mathrm{C}]$, as the presence of a metal-carbon double bond does not find any experimental evidence.

Alkylidene complexes with no heteroatoms are particularly stable and easy to prepare for early-transition elements. By contrast, for late-transition metals the synthesis of alkylidene complexes is more difficult, particularly for cationic compounds, and isolating species of this kind remains a challenging goal in many cases. It is also worth mentioning the peculiar reactivity of late-transition metal alkylidene complexes which, in spite of their structural analogy with Schrock carbenes, often, albeit not always (vide infra), show strongly electrophilic behavior, typical of Fischer carbenes. 


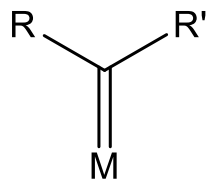

(a)

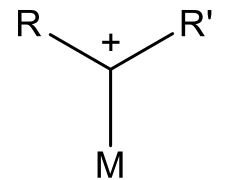

(b)

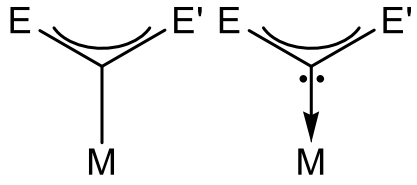

(c)

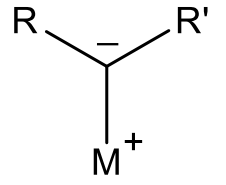

(d)

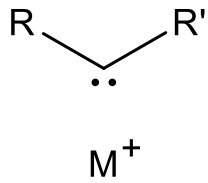

(e)

Figure 2. Schematic representations of metal-carbene bonds $\left(R, R^{\prime}=H\right.$, hydrocarbyl; $E, E^{\prime}=$ heteroatom)

Figure 2 shows four possible representations of a metal carbene-bond. Type (a) depicts a metal-carbon double bond, which is typical of Schrock-carbenes. The second representation (b) is most commonly used by organic chemists in proposed catalytic intermediates and indicates a metal-stabilized carbocation (carbenoid), stressing its intrinsic electrophilicity. Model (c) emphasizes the $\sigma$ component of the M-C bond, typical of Fischer-carbenes, and is predominantly used for NHC carbenes, for which the $\pi$ contribution to the bonding is small or even negligible. Finally, the last two representations (d) and (e) are quite uncommon and indicate nucleophilic nonheteroatom stabilized alkylidenes and carbenoids, respectively. Regrettably, no strict rules for the use of these representations have been established yet.

As briefly mentioned earlier, in this article we present an overview of the chemistry of alkylidene complexes of late transition metals. Regarding the metal centre, we concentrate exclusively on the latest transition elements, $\mathrm{Ni}, \mathrm{Pd}$ and $\mathrm{Pt}$, and $\mathrm{Cu}, \mathrm{Ag}$ and $\mathrm{Au}$. Concerning the ligands, only non-heteroatom-substituted carbenes are considered, although $\mathrm{R}$ and $\mathrm{R}^{\prime}$ of the $\mathrm{M}=\mathrm{CRR}$ ' unit might contain heteroatoms not directly bound to the carbene carbon atom and/or form part of a metallacyclic structure. Cycloheptatrienylidene or cylclopropylidene complexes, which have mainly been described for group 10 metals, are also excluded from this review in light of their special bonding situation dominated by the involvement of the carbon $p$ orbital in the aromatic system. Although in most cases the coordinated carbene ligand features electrophilic reactivity, i.e. Fischer-type behavior, some highly relevant examples of nucleophilic alkylidenes (Schrock complexes) have been reported in the last two decades. Special emphasis is made on synthetic and reactivity aspects concerning isolated and well-characterized species. The first part of each section is dedicated to the first discoveries in the field, while the following discussions are centered on more recent findings. As the following sections will make clear, these complexes constitute a 
young family of compounds, for the majority of its members have been discovered in the years elapsed since the turning of the century. Finally, as already evinced in the foregoing lines, the terminology used will follow the IUPAC recommendations summarized in the early literature, ${ }^{21}$ which are essentially coincident with the more recent Bochmann's guidelines. ${ }^{22 a}$

\section{Group 10 metals.}

As mentioned before, in spite of the plethora of complexes of group 10 metals with carbene ligands described to date, only a few of them can be included in the restricted family of alkylidene compounds that lack of heteroatom stabilization. The first compound of this type was reported in 2002 in a landmark publication by Mindiola and Hillhouse. ${ }^{28}$ Taking advantage of the isolobality of the $\left[\mathrm{NiL}_{2}\right]$ fragment with the $\mathrm{CH}_{2}$ group and of the steric protection provided by the 1,2-bis(di-tert-butylphosphino)ethane (dtbpe) ligand, the authors reacted the $\mathrm{Ni}(0)$ precursor $\mathrm{Ni}(\mathrm{dtbpe})(\mathrm{cod})$ (cod $=1,5-$ cyclooctadiene) with the diazocompound $\mathrm{N}_{2} \mathrm{CPh}_{2}$, to generate firstly the diphenyldiazomethane complex (dtbpe) $\mathrm{Ni}\left(\mathrm{N}, \mathrm{N}^{\prime}: \eta^{2}-\mathrm{N}_{2} \mathrm{CPh}_{2}\right)$, which decomposed thermally to afford the alkylidene complex $\mathrm{Ni}(\mathrm{dtbpe})\left(\mathrm{CPh}_{2}\right)(\mathrm{Scheme} 1)$.

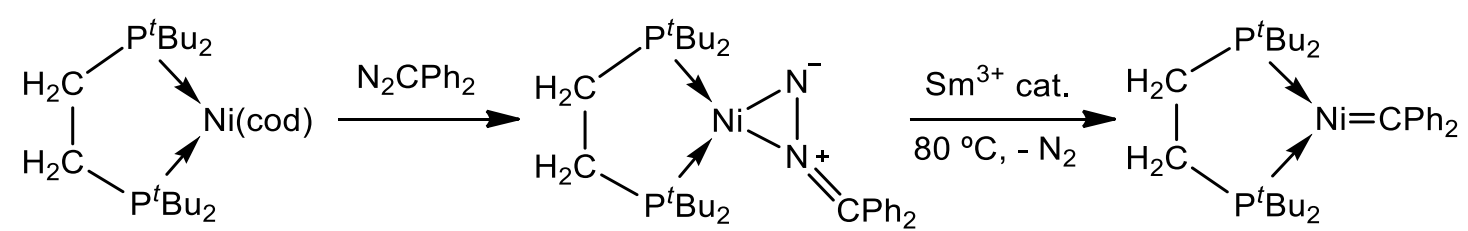

1

Scheme 1. The synthesis of the first Ni alkylidene (1), reported by Mindiola and Hillhouse in 2002.

The Ni-C bond was described as a double bond based on spectroscopic and structural properties, which is reasonable for a metal in a low oxidation state that receives further electron-density from the strongly $\sigma$-donating phosphorus atoms. In the same contribution the authors described several reactions of complex 1 (vide infra). One year after this report by Hillhouse, Bröring and collaborators published the first nonheteroatom stabilized carbene complex of $\mathrm{Pd}(\mathrm{II}), 2$, also containing a $\mathrm{CAr}_{2}$ fragment, prepared by treatment of a tripyrrinate derivative of $\mathrm{Pd}(\mathrm{II})$ with $p$-tolyldiazomethane ( $p$ $\left.\mathrm{TolCN}_{2}\right)$ in the presence of $\mathrm{NaBAr}^{\mathrm{F}}\left(\mathrm{BAr}^{\mathrm{F}}=\right.$ tetrakis[3,5bis(trifluoromethyl)phenyl]borate). ${ }^{29}$ 

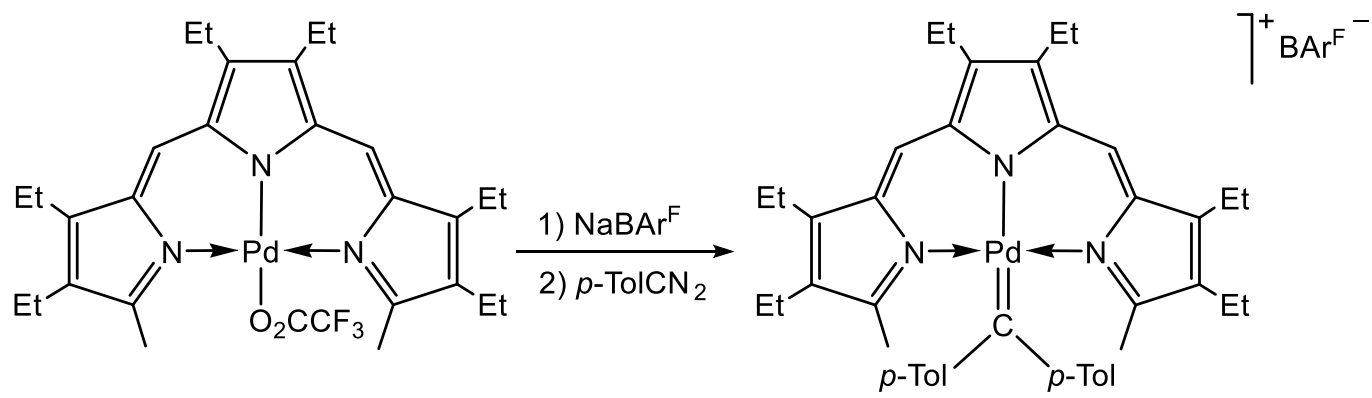

2

Scheme 2. The synthesis of the first Pd(II) alkylidene (2), reported by Bröring and coworkers in 2003.

Finally, only five years ago we reported on the first Pt(II) alkylidene, which was characterized in solution at low temperature. ${ }^{30}$ The $[\mathrm{Pt}=\mathrm{CHR}]^{+}$unit was generated by $\alpha$ hydride abstraction from a $\mathrm{Pt}-\mathrm{CH}_{2}$ group that forms part of a sterically protected platinacycle, obtained by cyclometallation of the bulky ${ }^{i} \operatorname{Pr}_{2} X y l$ phosphine $(X y l=2,6-$ $\mathrm{Me}_{2} \mathrm{C}_{6} \mathrm{H}_{3}$ ). Due to its enhanced reactivity and thermal instability, this compound could not be isolated in the solid state, but its alkylidene structure was demonstrated by reactivity studies and NMR spectroscopy.
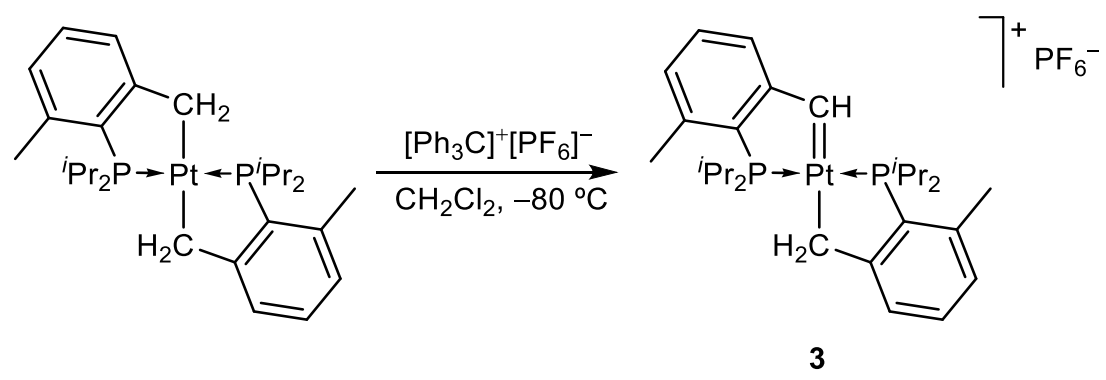

Scheme 3. Generation of the first Pt(II) alkylidene (3) to be characterized in solution.

\subsection{Nickel}

Even in light of the intrinsic high reactivity of these species that makes difficult their isolation, it is quite surprising that after the Hillhouse's report of $2002^{28}$ no further examples of well-characterized $\mathrm{Ni}$ alkylidenes have appeared in the literature until 2013. It seems appropriate to discuss in this section the few reactions of complex $\mathbf{1}$ reported to date. The original contribution by Mindiola and Hillhouse disclosed the reactivity of the $\mathrm{Ni}$ alkylidene $\mathbf{1}$ towards a series of small molecules of different characteristics, namely $\mathrm{CO}, \mathrm{CO}_{2}, \mathrm{SO}_{2}, \mathrm{O}=\mathrm{C}=\mathrm{CPh}_{2}$, and $\mathrm{HNMe}_{2} \mathrm{Ph}^{+}$(Scheme 4). 
Considering the products of the reactions of Scheme 4, it seems evident that carbene complex (dtbpe) $\mathrm{Ni}=\mathrm{CPh}_{2}$ exhibits a clear nucleophilic character, unambiguously demonstrated, for instance, by the reaction with $\mathrm{H}^{+}$which produces the alkyl complex 4.

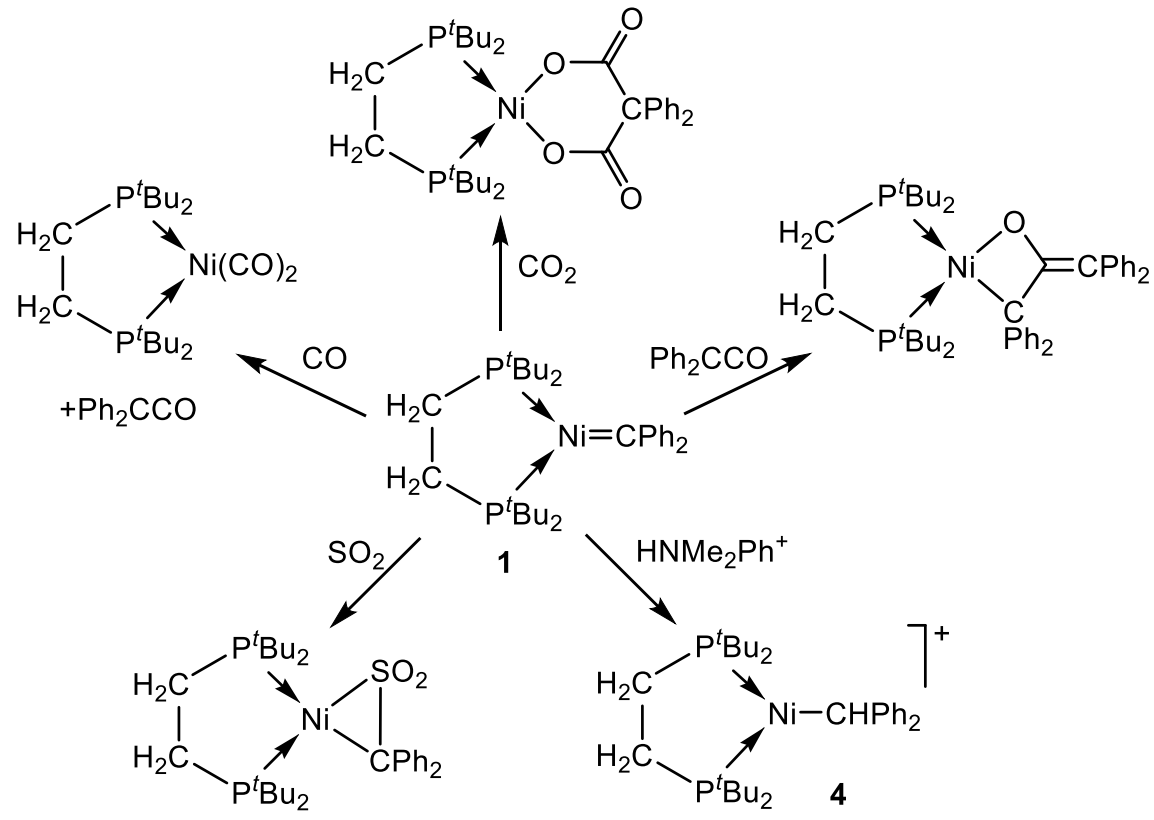

Scheme 4. Reactivity of the alkylidene complex 1.

Further work from the same group centered on the reactions of ethylene with the carbene, imido and phosphinidene complexes (dtbpe) $\mathrm{Ni}(=\mathrm{X})$, where $\mathrm{X}$ represents $\mathrm{CPh}_{2}$ (i.e. complex 1), NAr, and PAr'. Transfer of the $\mathrm{X}$ group to $\mathrm{C}_{2} \mathrm{H}_{4}$ was observed, forming the respective cyclopropane, aziridine and phosphirane products. ${ }^{31}$

In a combined theoretical and experimental study, ${ }^{32}$ Hillhouse and Cundari described in 2009 some reactions of the $\mathrm{Ni}$ (II) alkylidene 1 with the energy-rich molecules $\mathrm{N}_{2} \mathrm{O}$ and $\mathrm{RN}_{3}(\mathrm{R}=$ adamantyl (Ad), mesityl (Mes)). In both cases, the first step of the calculated reaction path is the 1,3-dipolar addition of the $\mathrm{N}_{2} \mathrm{X}(\mathrm{X}=\mathrm{O}, \mathrm{NMe})$ species to the nickel carbene with formation of a 5-membered ring intermediate, $\mathbf{5}$. With $\mathrm{X}=\mathrm{O}$, dinitrogen extrusion from the cyclometallated fragment affords the final $\eta^{2}-C, O$ benzophenone adduct, which interestingly may be regarded as the product of an organometallic version of alkene epoxidation (Scheme 5, a). On the other hand, reactions with azides $(\mathrm{X}=\mathrm{NR})$ gave imido complexes as the ultimate product of series of reactions involving $\mathrm{N}_{2}$ liberation, formal nitrene-carbene coupling, coordination of a second equivalent of $\mathrm{N}_{3} \mathrm{R}$ to the (dtbpe) $\mathrm{Ni}(0)$ fragment and again $\mathrm{N}_{2}$ extrusion (Scheme $5, \mathrm{~b})$. 


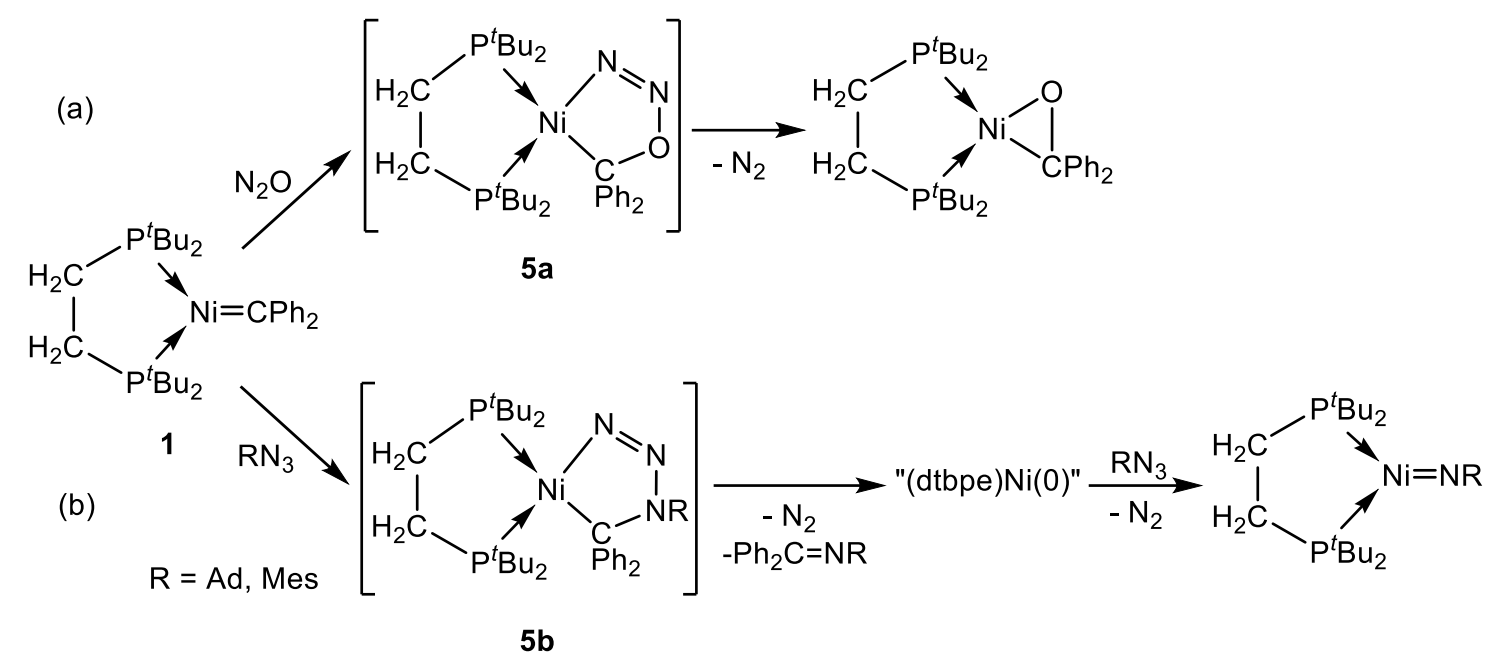

Scheme 5. Reactions of complex 1 with $\mathrm{N}_{2} \mathrm{O}$ and azides.

In 2013 Piers and collaborators reported on strongly donating nucleophilic carbenes of $\mathrm{Ni}(\mathrm{II}), \mathbf{6} \mathbf{a}$ and $\mathbf{6 b}$, in which the $\mathrm{Ni}=\mathrm{C}$ linkage is generated by stepwise deprotonation of a Ni-methylene group (Scheme 6). ${ }^{33}$ The cyclometallated PCP ligand that incorporates the $\mathrm{Ni}-\mathrm{CH}$ or $\mathrm{Ni}=\mathrm{C}$ fragments plays a key role not only in the stabilization of the carbene species but also in the activation of the E-H bond of diverse small molecules such as dihydrogen $(\mathrm{E}=\mathrm{H})$, water $(\mathrm{E}=\mathrm{OH})$, methanol $\left(\mathrm{E}=\mathrm{CH}_{3} \mathrm{O}\right)$, ammonia $\left(\mathrm{E}=\mathrm{NH}_{2}\right.$, reversible addition) and phenylacetylene $(\mathrm{E}=\mathrm{PhC} \equiv \mathrm{C})$. These reactions are fast and occur with addition of the $\mathrm{E}-\mathrm{H}$ bond across the $\mathrm{Ni}=\mathrm{C}$ bond, thereby constituting and interesting example of metal-ligand cooperativity. Thus, the rupture of the E-H bond generates a new Ni-E linkage and converts the $s p^{2}$ carbene carbon atom into a cyclometallated $\mathrm{HC}_{s p 3}$ methyne, as in the parent alkyl-type complex.

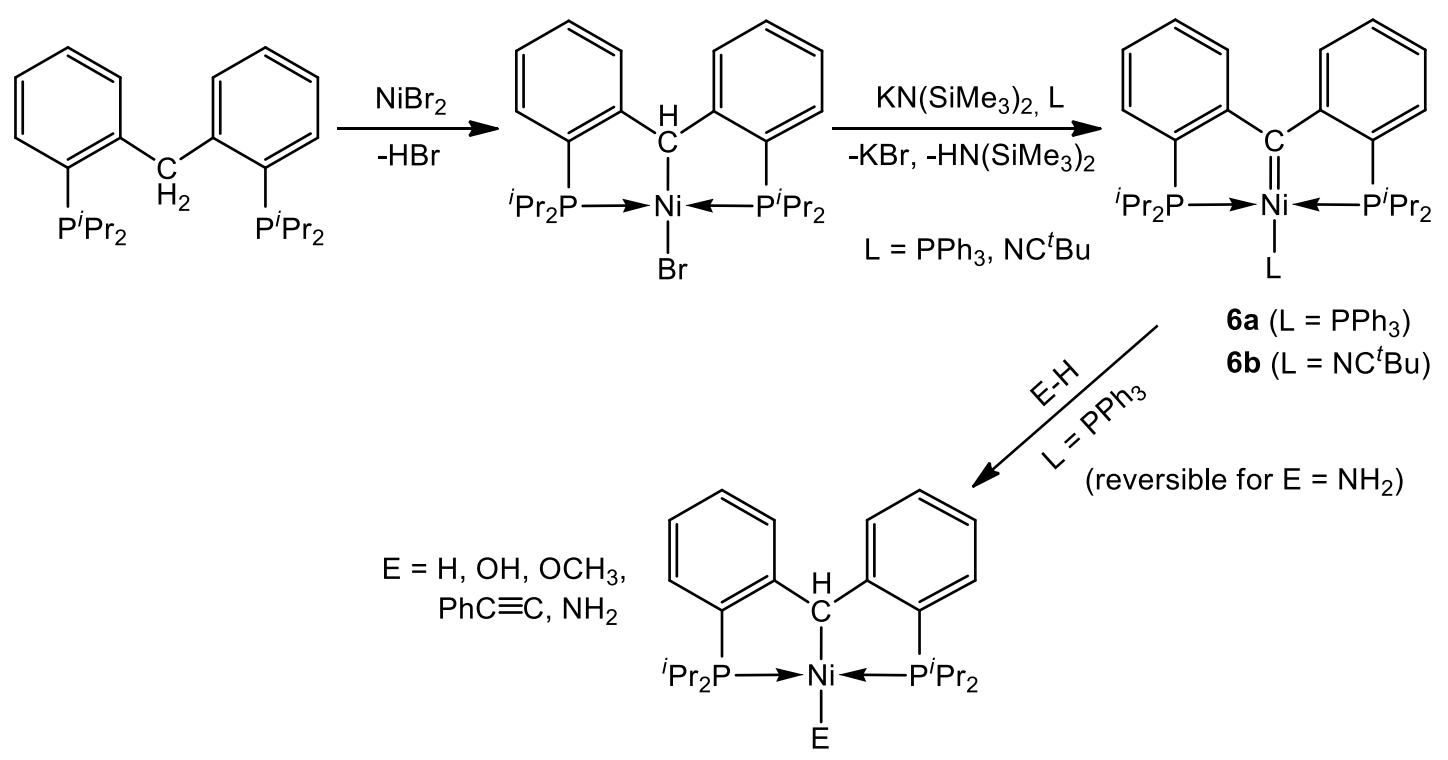


Scheme 6. Synthesis and reactions with E-H molecules of complexes $\mathbf{6 a}$ and $\mathbf{6 b}$.

Analogously to alkylidene $\mathbf{1}$, complexes $\mathbf{6}$ are described as Ni(II) complexes, with the carbene ligand acting as a non-innocent Schrock-type dianionic carbene. Structural data also support this assumption. $\mathrm{X}$-ray studies revealed longer $\mathrm{Ni}=\mathrm{C}$ bonds than in $\mathbf{1}(1.908(5), \mathbf{6 a} ; 1.927(4), \mathbf{6 b} ; v s 1.836(2) \AA$ in $\mathbf{1})$ probably as a reflection of the higher coordination number in Piers' complex. More recently, the activation of small molecules induced by Piers' complex has theoretically been studied by Xie and coworkers. $^{34}$

The possibility of generating $\mathrm{Ni}(\mathrm{III})$ carbenes through one-electron oxidation processes from Ni(II) species was explored by Iluc and Hillhouse, who reported in 2014 on two similar trigonal planar $\mathrm{Ni}(\mathrm{II})$ alkylidenes, $\mathbf{7 a}$ and $\mathbf{7 b}$, again stabilized by bulky diphosphine ligands $\left(\mathrm{P}^{\wedge} \mathrm{P}\right)$, and their reactions with a ferricinium salt. ${ }^{35}$ Complexes $7 \mathbf{a}$ (with $\mathrm{P}^{\wedge} \mathrm{P}=$ dtbpe) and $\mathbf{7 b}$ (with $\mathrm{P}^{\wedge} \mathrm{P}=$ bis(diisopropylphosphino)naphthalene) were prepared by photochemical decomposition of the parent diazocompounds with liberation of $\mathrm{N}_{2}$ (Scheme 7). The bis(phosphine)naphtalene complex $\mathbf{7 b}$ exhibits unusual stability thanks to the highly crowded environment around the metallic core and the rigidity of the $\mathrm{P}^{\wedge} \mathrm{P}$ ligand. Interestingly, the existence of a highly sterically demanding terphenyl group as substitutent of the carbene carbon atom permitted for the first time the isolation of a $\mathrm{Ni}$ alkylidene of the type $\mathrm{Ni}=\mathrm{CHAr}$, that is with a hydrogen atom directly bound to the carbenic carbon atom. While the Ni(II) alkylidenes 7 could be viewed as members of the Schrock family, that is nucleophilic and with a formal dianionic $\mathrm{CR}_{2}$ ligand by analogy with the two examples mentioned above, the dtbpederived cationic $\mathrm{Ni}(\mathrm{III})$ alkylidene, 8a, proved to be highly electrophilic as demonstrated by the formation of the ylide 9, resulting from nucleophilic attack of one of the $\mathrm{P}$ atoms to the $[\mathrm{Ni}=\mathrm{CHR}]^{+}$carbon. Interestingly, the oxidation reaction is reversible, such that treatment of ylid complex 9 with $\mathrm{KC}_{8}$ yields back the corresponding $\mathrm{Ni}(\mathrm{II})$ alkylidene. The reversibility of the transformation is also supported by cyclic voltammetry data. 


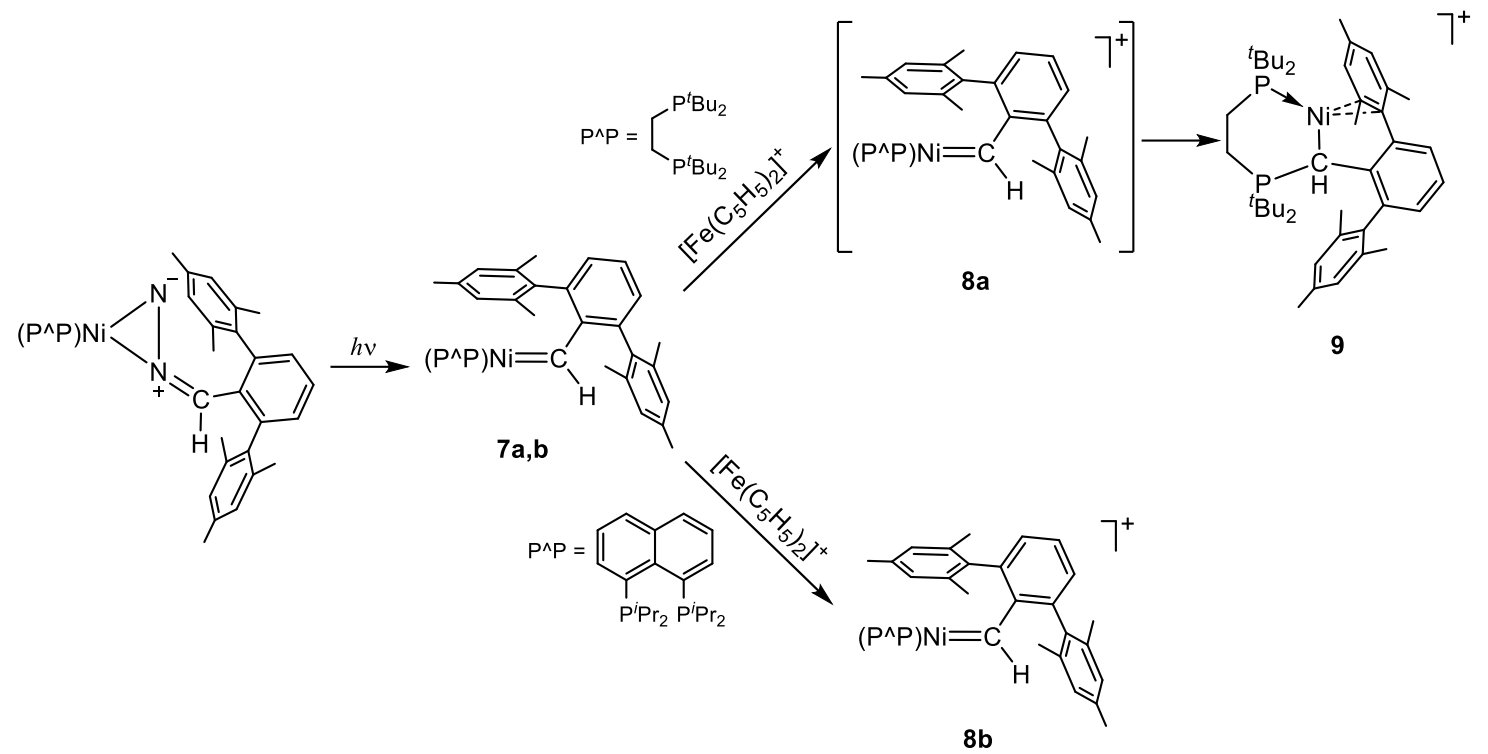

Scheme 7. Synthesis and one-electron oxidation of the terphenyl substituted alkylidenes 7.

Notably, the rigidity provided by the diphosphinonaphtalene ligand in $\mathbf{7 b}$ allowed for the isolation of the cationic $\mathrm{Ni}$ (III) carbene complex $\mathbf{8 b}$, which could also be converted back into the parent neutral carbene by one-electron reduction with $\mathrm{KC}_{8}$. Moreover, this study offers a concise description of the electronic structure of complex 7a drawn by DFT methods. The HOMO is a bonding orbital of $\pi$ symmetry resulting from the combination of the $d_{\mathrm{x}^{2}-\mathrm{y}^{2}}$ of the metal and the $p_{\mathrm{x}}$ orbital of the carbene carbon atom, while the LUMO is the antibonding orbital corresponding to the $\sigma \mathrm{Ni}-\mathrm{C}$ bond.

To best of our knowledge, beyond the few complexes discussed above no further alkylidene complexes of nickel lacking heteroatom substituents have been isolated and described. Nevertheless, species of this kind are often invoked as reaction intermediates in catalytic and stoichiometric transformations. For instance Chen proposed in 2015 the formation of a $\mathrm{Ni}=\mathrm{CH}_{2}$ fragment in the cyclopropanation of alkenes catalyzed by $\mathrm{Ni}$ (II), by using the in situ generated lithiomethyl trimethylammonium triflate as the methylene source. ${ }^{36}$ Besides, Louie and collaborators prepared a series of $\mathrm{Ni}(\mathrm{II})$ ketene complexes stabilized by the chelating bis(diphenylphosphino)ferrocene ligand and studied their thermal decomposition by kinetic experiments and DFT calculations. ${ }^{37}$ Although no intermediates were detected, the authors proposed that the decarbonylation reaction, that eventually produces an alkene and a $\mathrm{Ni}(0)$ carbonyl complex, implies the rupture of the $\mathrm{C}=\mathrm{CO}$ double bond of the coordinated ketene with subsequent formation of a $\mathrm{Ni}$ alkylidene (Scheme 8). 


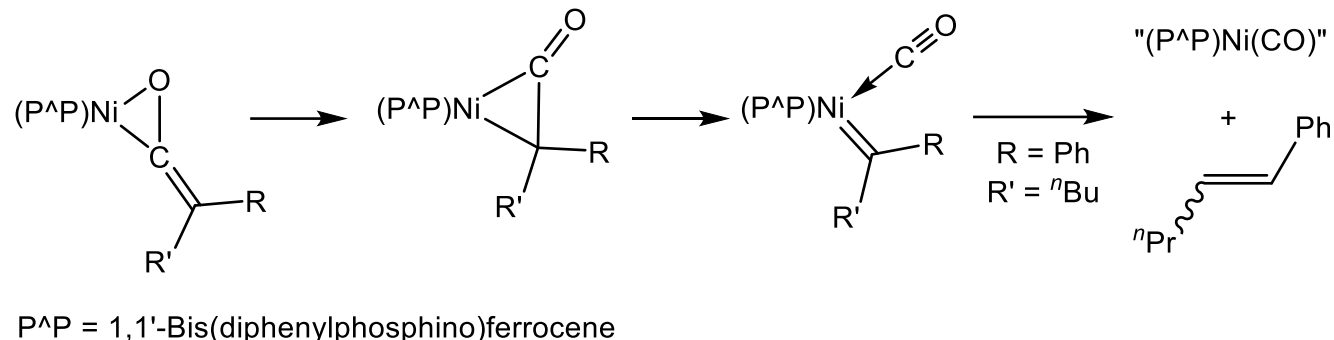

Scheme 8. Ni alkylidenes are proposed as reaction intermediates in the decomposition of $\mathrm{Ni}(\mathrm{II})$ ketene complexes.

To conclude this section, it is worth remarking that some 15 years after the discovery of the first non-heteroatom substituted nickel alkylidene, the number of complexes of this type is unquestionably exiguous, evincing that nickel complexes with carbene ligands void of heteroatoms remain highly elusive species. Nonetheless, highly attractive observations made in the last years, such as the reversible addition of ammonia to the $\mathrm{Ni}=\mathrm{C}$ bond (see Scheme 6) and the also reversible one-electron processes of Scheme 7, will likely stimulate further studies in this attractive area of research.

\subsection{Palladium}

As for the analogous species of its lighter congener, non-heteroatom stabilized palladium alkylidenes are very rare compounds and, since the first complex reported by Bröring et al. in $2003,{ }^{29}$ no other complexes of this class appeared in the literature until 2007, although in 2004 Raubenheimer and coworkers described some $\mathrm{Pd}(\mathrm{II})$ and $\mathrm{Pt}(\mathrm{II})$ compounds derived from quinolinone and quinolinium fragments. ${ }^{38}$ As shown in

Scheme 9, the carbene carbon atom of these complexes does not bear heteroatom substituents, though it is part of an aromatic system.

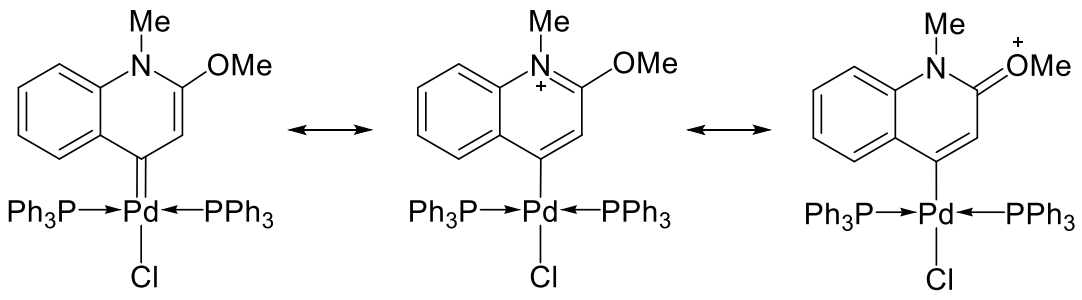

Scheme 9. Resonance structures for quinolinium complexes reported by Raubenheimer in 2004. 
In 2007, Ozerov and coworkers generated an electrophilic palladium(II) alkylidene, 10, using a sterically demanding $\mathrm{PC}_{\text {carbene }} \mathrm{P}$ pincer ligand. ${ }^{39}$ The free ligand, described by the authors as pincer "proto-ligand" due to the presence of a $\mathrm{PCH}_{2} \mathrm{P}$ entity, was converted into a tridentate PCHP phosphine-alkyl-phosphine palladium chelate (Scheme 10) by the action of a base. A second deprotonation was not, however, feasible even in the presence of $\mathrm{NaN}\left(\mathrm{SiMe}_{3}\right)_{2}$ or by action of alkyl derivatives of lithium, magnesium or zinc.

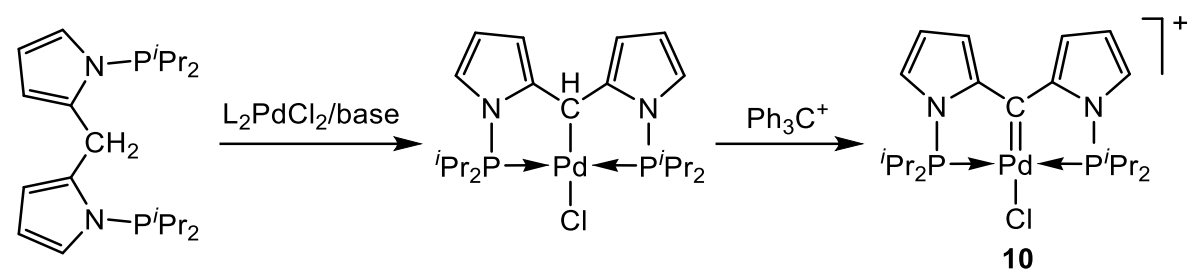

Scheme 10. Synthesis of the alkylidene complex 10 starting from a pincer "proto-ligand".

The latter reactions produced instead the corresponding square-planar (PCHP)PdR palladium(II) alkyl derivatives, but the authors succeeded in making a cationic, squareplanar $\mathrm{Pd}(\mathrm{II})$ carbene $\left[\mathrm{PC}_{\text {carbeneP }} \mathrm{PdCl}\right]^{+}, \mathbf{1 0}$, by a classical $\alpha$-hydride abstraction with $\mathrm{Ph}_{3} \mathrm{C}^{+} \mathrm{X}^{-}\left(\mathrm{X}=\mathrm{PF}_{6}, \mathrm{BAr}_{\mathrm{F}}\right)$ (Scheme 10). Based on structural considerations the $\mathrm{Pd}-\mathrm{C}$ interaction was described as a $\sigma$ bond with minimal $\pi$ backbonding from the poor $\pi$ basic $\mathrm{Pd}(\mathrm{II})$ centre to the carbene carbon. No reactivity studies were reported.

Once again, and now for a time period of nearly seven years, the transition metal carbene literature was devoid of examples of palladium complexes of carbene ligands with no heteroatom substituents. Somewhat surprisingly, and thanks to the work of Iluc and coworkers, our knowledge of these species has been significantly expanded in the last three years, by reason of the discovery of new types of palladium complexes containing carbene ligands of diverse structure and chemical reactivity. The most relevant, truly noteworthy results from the group of Iluc stem from the use of the [2diisopropylphosphino)phenyl] methane precursor, i.e. a $\mathrm{PCH}_{2} \mathrm{P}$-containing diphosphine ligand capable of converting into the corresponding $\mathrm{PC}_{\text {carbene }} \mathrm{P}$ pincer ligand, by formal deprotonation as demonstrated by Piers et al. with the already cited synthesis of related nickel complexes (see Scheme 6). Before reviewing these results, it is worth mentioning briefly that the same researchers have reported very recently an unstable trigonal-planar Pd di(p-tolyl)carbene complex, 11, bonded to a diphosphine ligand consisting of two 
$\operatorname{PPr}_{2}{ }_{2}$ termini bridged by a terphenyl linker (Scheme 11). ${ }^{40}$ The complex was characterized in solution by NMR spectroscopy and found to feature NMR properties similar to those of the more stable platinum analogue (vide infra).

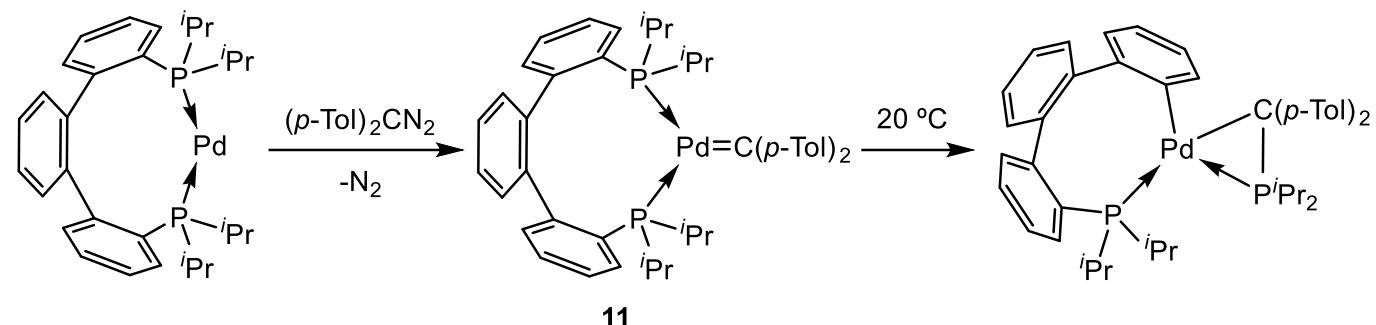

Scheme 11. Formation and decomposition of the alkylidene complex 11.

For instance, the $\mathrm{Pd}=\mathrm{C}$ carbon resonates at $296.6 \mathrm{ppm}$ and exhibits a ${ }^{2} J_{\mathrm{CP}}$ coupling of 63 $\mathrm{Hz}$ (262.8 ppm and $66 \mathrm{~Hz}$ for the Pt analogue). At room temperature, the palladium alkylidene decomposed with cleavage of a P-aryl bond (Scheme 11) and formation of a new $\mathrm{P}-\mathrm{C}$ bond involving the carbene ligand. Reactivity studies of the $\mathrm{Pd}=\mathrm{C}$ bond were hampered by the instability of the complex.

Using Piers' bis[2-(disopropylphosphino)phenyl] methane parent ligand, that as already discussed permitted the isolation of an interesting nickel complex containing a strongly donating nucleophilic carbene terminus (see Scheme 6), Comanescu and Iluc generated first a square-planar $\left(\mathrm{PCH}_{\text {alkyl }} \mathrm{P}\right) \mathrm{PdCl}$ complex, which upon further dehydrohalogenation by action of $\mathrm{KN}\left(\mathrm{SiMe}_{3}\right)_{2}$ produced a palladium carbene (12a) with the expected nucleophilic reactivity, as evidenced by the reactions summarized in Scheme 12.41 To emphasize this property, the authors proposed a zwitterionic representation of the Pd-carbene bond with a formal negative charge on the carbene carbon atom. X-ray data for the two complexes $\left(\mathrm{PMe}_{3}\right.$ and $\left.\mathrm{PPh}_{3}\right)$ support single bond character for the $\mathrm{Pd}-\mathrm{C}_{\text {carbene }}$ bond, which was also in agreement with computational calculations. 


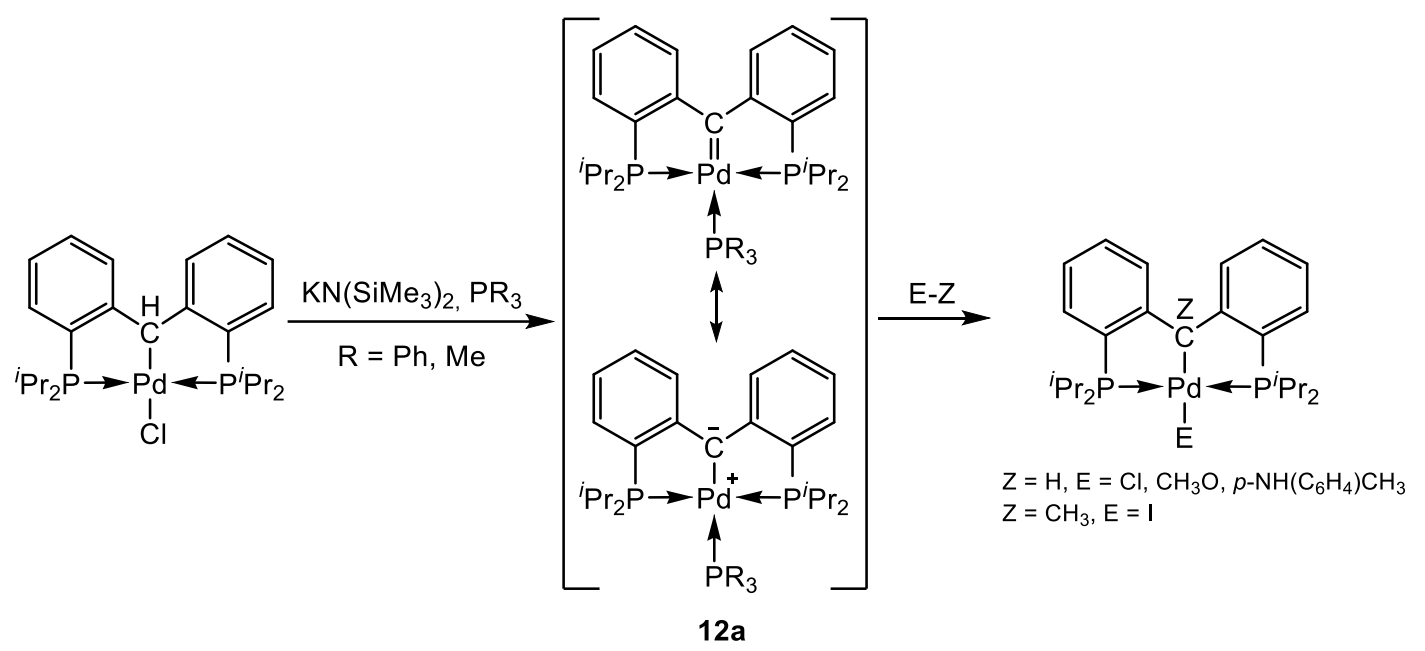

Scheme 12. Formation of the alkylidene complex 12a and its reactions with E-Z species.

DFT studies reveal the existence of three occupied molecular orbitals of $\sigma$ and $\pi$ symmetry, two bonding and one antibonding, which leads to a Pd-C bond order of 1 , as confirmed by NBO analysis.

The reactivity of complexes $\mathbf{1 2 a}$ and $\mathbf{1 2 b}$ with $\mathrm{B}\left(\mathrm{C}_{6} \mathrm{~F}_{5}\right)_{3}$ was also explored and some similarities between frustrated Lewis pairs and the nucleophilic palladium alkylidene recognized (Scheme 13). ${ }^{42}$ Thus, the crowded environment around the carbenic carbon atom, which would be the usual target of electrophilic attacks, led to unexpected products resulting from the activation of a C-F bond of the borane (Scheme $13, \mathrm{~b})$ or the dearomatization of a phenyl ring of the ligand (Scheme 13, a). Accordingly, when $\mathrm{R}=\mathrm{H}$ (12a) the accessibility of the para position (relative to the alkylidene) in combination with the enhanced electron density at the para carbon atom, resulted in the formation of the zwitterionic complex 13 with a dearomatized phenyl ring (Scheme 13, a).

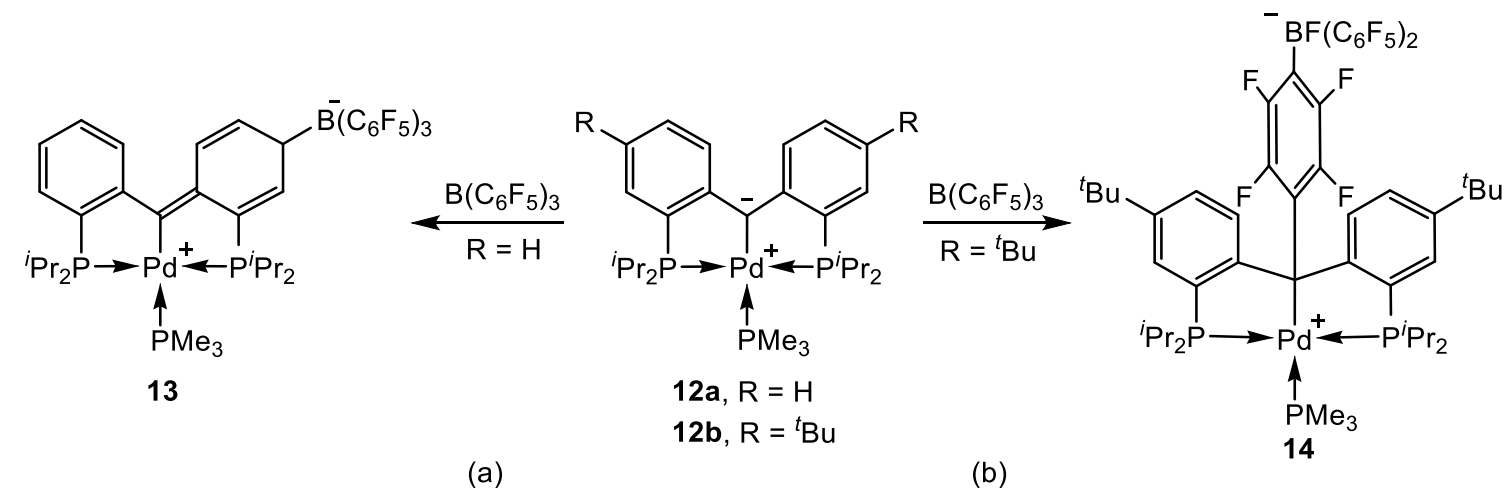

(a)

(b)

Scheme 13. Reactions of the alkylidene complexes 12 with $\mathrm{B}\left(\mathrm{C}_{6} \mathrm{~F}_{5}\right)_{3}$. 
Conversely, when $\mathrm{R}={ }^{t} \mathrm{Bu}(\mathbf{1 2 b})$, the carbene carbon atom is able to cleave a $\mathrm{C}-\mathrm{F}$ of a $\mathrm{C}_{6} \mathrm{~F}_{5}$ ring with formation of the ylide 14 (Scheme 13, b). It is noteworthy that the expected formation of a new C-B bond was not observed, which is to ascribe to steric reasons. The parallelism with frustrated Lewis pairs became also evident when zwitterionic complexes $\mathbf{1 3}$ and $\mathbf{1 4}$ were generated in situ in the presence of dihydrogen. Under these conditions products resulting from $\mathrm{H}_{2}$ splitting were detected.

The reactivity of the nucleophilic palladium alkylidene containing coordinated $\mathrm{PMe}_{3}\left(\mathrm{PC}_{\text {carbene }} \mathrm{P}\right) \mathrm{Pd}\left(\mathrm{PMe}_{3}\right)$ toward $\mathrm{C}-\mathrm{H}$ bonds of different acidity was also tested (Scheme 14). ${ }^{43}$ For instance, $\mathrm{PhC} \equiv \mathrm{CH}$, with $p \mathrm{~K}_{a}=28.7$, underwent $\mathrm{C}-\mathrm{H}$ addition across the $\mathrm{Pd}-\mathrm{C}$ bond, with formation of the alkenyl-( $\left.\mathrm{PC}_{\text {alkyl}} \mathrm{P}\right)-\mathrm{Pd}(\mathrm{II})$ complex, $\left[\mathrm{PC}(\mathrm{H})_{\text {alkyl }} \mathrm{P}\right] \mathrm{Pd}(\mathrm{C} \equiv \mathrm{CPh})$.

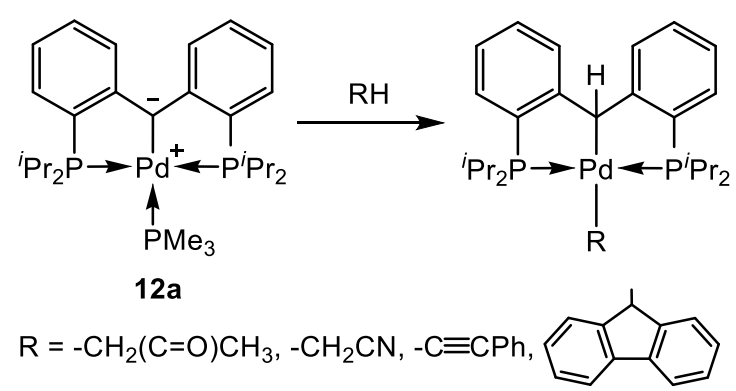

Scheme 14. C-H activation reactions at the alkylidene complex 12a.

In contrast, no observable reaction took place with diphenylmethane, which was attributed to its low Brönsted-Lowry acidity $(\mathrm{pKa}=32.2)$. It was actually concluded that the observed reactivity was controlled by the $\mathrm{pKa}$ value, such that substrates with $p K a$ higher than 29 do not react even after prolonged heating.

Recently, these studies on the activation of $\mathrm{C}-\mathrm{H}$ bonds by the ylid-type palladium alkylidene, have been extended to other $\mathrm{E}-\mathrm{H}$ bonds $(\mathrm{E}=\mathrm{B}, \mathrm{Si}, \mathrm{Ge}) .{ }^{44} \mathrm{In}$ spite of the contrasted nucleophilicity of the carbene ligand in these complexes (Scheme 15), the regioselectivity of the formal addition of the E-H bond to the palladium-carbene bond is governed by the nature of the activated substrate and of the monodentate phosphine ligand $\left(\mathrm{PMe}_{3}\right.$ or $\left.\mathrm{PPh}_{3}\right)$. 


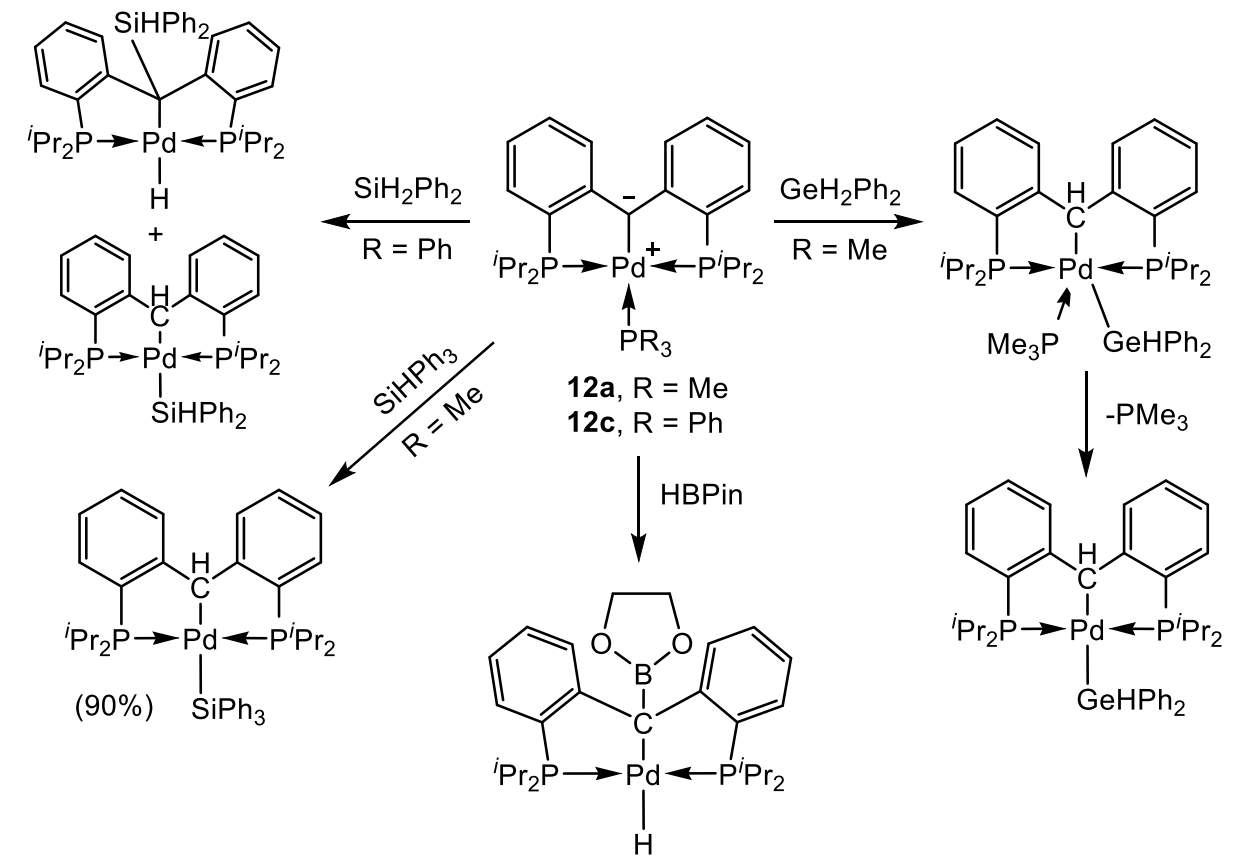

Scheme 15. B-H, Si-H, and Ge-H activation reactions at the alkylidene complexes 12a and 12c.

Notably, reaction of the triphenylphosphine derivative 12c with $\mathrm{Ph}_{2} \mathrm{SiH}_{2}$ yields a mixture of the $\mathrm{Pd}$-hydride $\left[\mathrm{PC}\left(\mathrm{SiHPh}_{2}\right) \mathrm{P}\right] \mathrm{PdH}$ and - silyl $[\mathrm{PC}(\mathrm{H}) \mathrm{P}] \mathrm{Pd}\left(\mathrm{SiHPh}_{2}\right)$ isomers in a ratio that varies with temperature. Moreover, the reaction of $\mathrm{GeH}_{2} \mathrm{Ph}_{2}$ permitted the isolation of an unusual pentacoordinate Pd(II) complex, which can be envisaged as an intermediate preceding $\mathrm{PMe}_{3}$ dissociation (Scheme 15).

Importantly, significant modifications of the $\left(\mathrm{PC}_{\text {carbene}} \mathrm{P}\right) \mathrm{Pd}$ scaffold affecting the palladium-carbene bond, and therefore the electronic properties of the carbene ligand, were successfully introduced by means of chemical and electrochemical methods. As depicted in Scheme 16, in addition to the ylid-type carbene structure characteristic of the above $\mathrm{PMe}_{3}$ and $\mathrm{PPh}_{3}$ complexes, related compounds with different electronic carbene structures have been obtained.

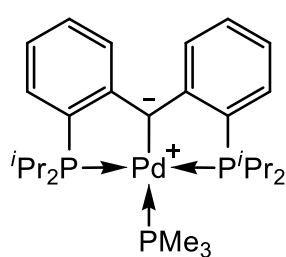

$12 a$

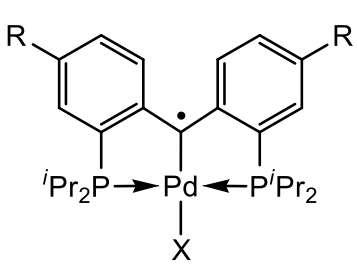
$\mathrm{X}=\mathrm{Cl}, \mathrm{Br}, \mathrm{I}, \mathrm{NH}(p-\mathrm{Tol})$, $\mathrm{CH}_{2} \mathrm{Ph}, \mathrm{NPh}_{2}$ 15

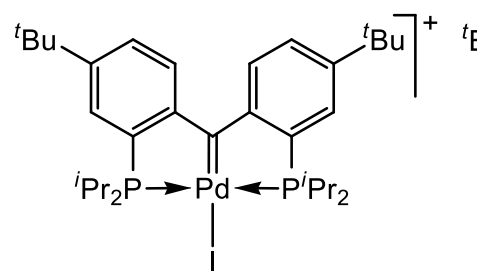

17

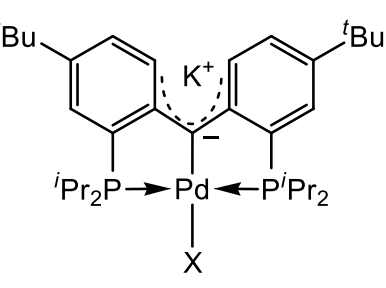

$\mathrm{X}=\mathrm{NH}(p$-tol $), \mathrm{CH}_{2} \mathrm{Ph}$

18

Scheme 16. Different types of palladium alkylidenes derived from the $\left[\mathrm{PC}_{\text {carbene }} \mathrm{P}\right]$ carbene ligand skeleton (refs. 40-47). 
Thus, oxidation of the $\mathrm{PMe}_{3}$, ylid-like alkylidene complex 12a with $\mathrm{Br}_{2}, \mathrm{I}_{2}$ or with $\mathrm{CH}_{2} \mathrm{X}_{2}(\mathrm{X}=\mathrm{Cl}, \mathrm{Br}, \mathrm{I})$ allowed the isolation of stable carbene radicals, 15a (Scheme 17). ${ }^{45}$ The new, four-coordinate complexes are monomeric and exhibit solution magnetic moments close to $1.8 \mu_{\mathrm{B}}$. EPR measurements revealed $g$-factors close to 2 , in accordance with the radical formulation proposed for the carbene ligand skeleton.

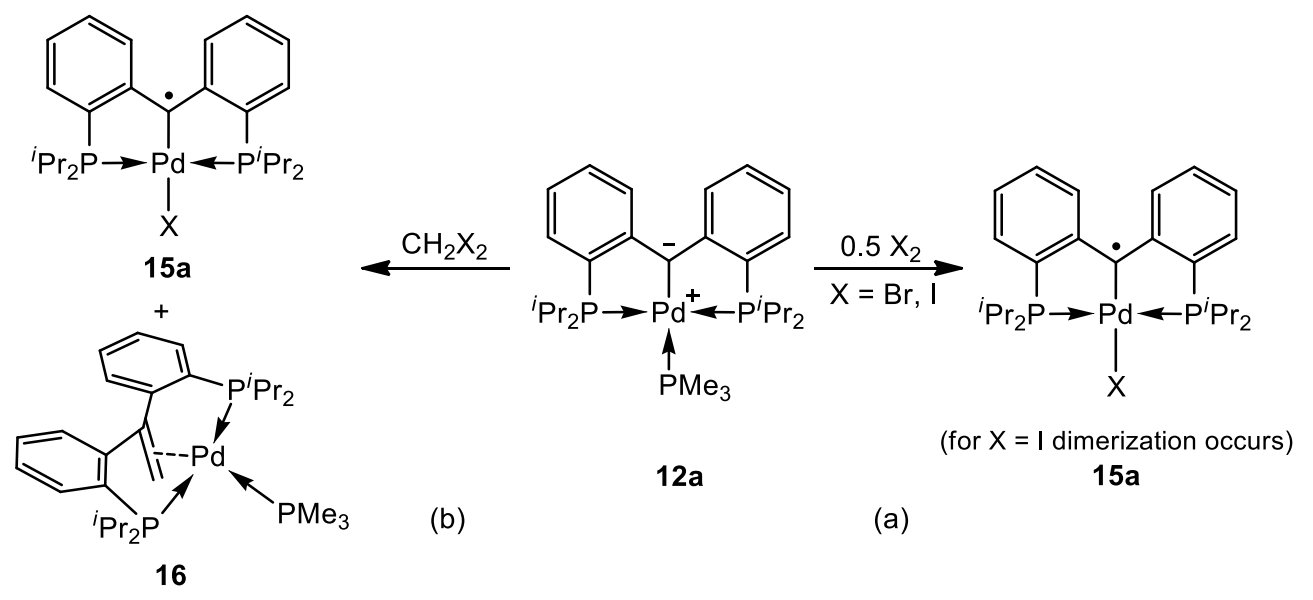

Scheme 17. Reactions of complex 12a with dihalogens and dihalomethanes yielding carbene radicals.

In addition to the paramagnetic radical complexes, the dihalomethane oxidations yielded a diamagnetic, four-coordinate $\mathrm{Pd}(0)$ complex $(\mathbf{1 6})$, exhibiting a $\left(\mathrm{P}\left(\mathrm{C}=\mathrm{CH}_{2}\right) \mathrm{P}\right)$ diphosphine-alkene tridentate ligand, resulting from the coupling of the methylene groups of the dihalomethane with the carbene carbon of the starting palladium alkylidene (Scheme 17b). ${ }^{45}$

Another interesting observation based on a neutral, strongly nucleophilic alkylidene complex 12b was the possibility to effect successive, reversible one-electron oxidation reduction reactions. ${ }^{46}$ As shown in Scheme 18 , a one-electron oxidation $(0.5$ equiv of $\mathrm{I}_{2}$ ) generated a stable carbene radical complex (15b) analogous to those already discussed (Scheme 17). Notice the ${ }^{t} \mathrm{Bu}$ substitution on the aryl backbone of the diphosphine-carbene ligand in the present system, which is aimed to prevent the relatively facile radical dimerization observed for the non-substituted complex analogue. ${ }^{42} \mathrm{~A}$ second oxidation, this time promoted by $\mathrm{Cp}_{2} \mathrm{Fe}^{+}$, yielded the cationic, strongly electrophilic alkylidene complex 17. 

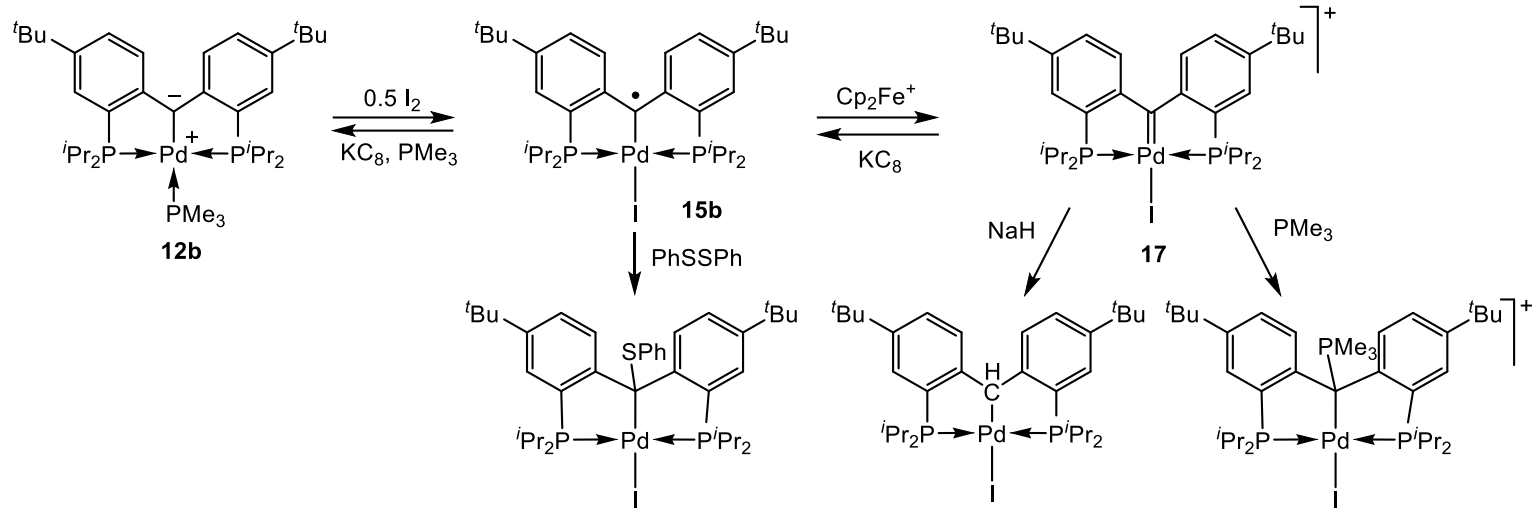

Scheme 18. Reversible one-electron oxidations of complex $\mathbf{1 2 b}$ and reactivity of the oxidized $\mathbf{1 5 b}$ and $\mathbf{1 7}$ complexes.

The three palladium alkylidenes of Scheme 18 feature square-planar geometry and $\mathrm{sp}^{2}$-hybridized carbene carbon, with Pd-C bond lengths which decrease regularly, from $2.076(3) \AA$ in $\mathbf{1 2} \mathbf{b}^{42}$ to $2.022(3)$ and $1.968(3) \AA$ in $\mathbf{1 5 b}$ and $\mathbf{1 7}$ respectively. As already mentioned, the Pd-C bond in the ylid-type complex $\mathbf{1 2 b}$ is better described as a single bond as a consequence of the antibonding $\pi$-type palladium-carbene nature of the HOMO, that compensates the $\pi$ bonding component residing in HOMO-10. ${ }^{41,42}$ Thus, the observed shrinkage of the $\mathrm{Pd}-\mathrm{C}$ bond is consistent with an increase in the palladiumcarbene bond order. Since the LUMO of the cationic alkylidene complex $\mathbf{1 7}$ has a similar antibonding $\pi$-type nature, successive addition of electrons should restore first the carbene radical and ultimately the ylid-type alkylidene. As can be seen in Scheme 18, these expectations were fulfilled chemically, employing $\mathrm{KC}_{8}$ as the reductant. Finally in this regard, the carbene reactivity illustrated in Scheme $18(\mathrm{PhSSPh}, \mathrm{NaH}$ and $\mathrm{PMe}_{3}$ ) is in full agreement with predictions and constitutes a most remarkable example of a reversible change in the reactivity of a metal-bound carbene ligand from nucleophilic (Schemes 14 and 15) to electrophilic through radical-type reactivity (Scheme 18).

Before closing this section there is yet one further contribution of the Iluc group that deserves attention. ${ }^{47}$ Metathesis of the iodide ligand of the radical alkylidene complex $\mathbf{1 5 b}$ of Scheme 19 by an amide or a benzyl group, followed by reduction with a suitable reagent, yielded unprecedented heterobimetallic palladium-potassium alkylidene complexes 18. The new compounds are diamagnetic and exhibit polymeric 
structures in the solid state, although they have good solubility properties in ether solvents.
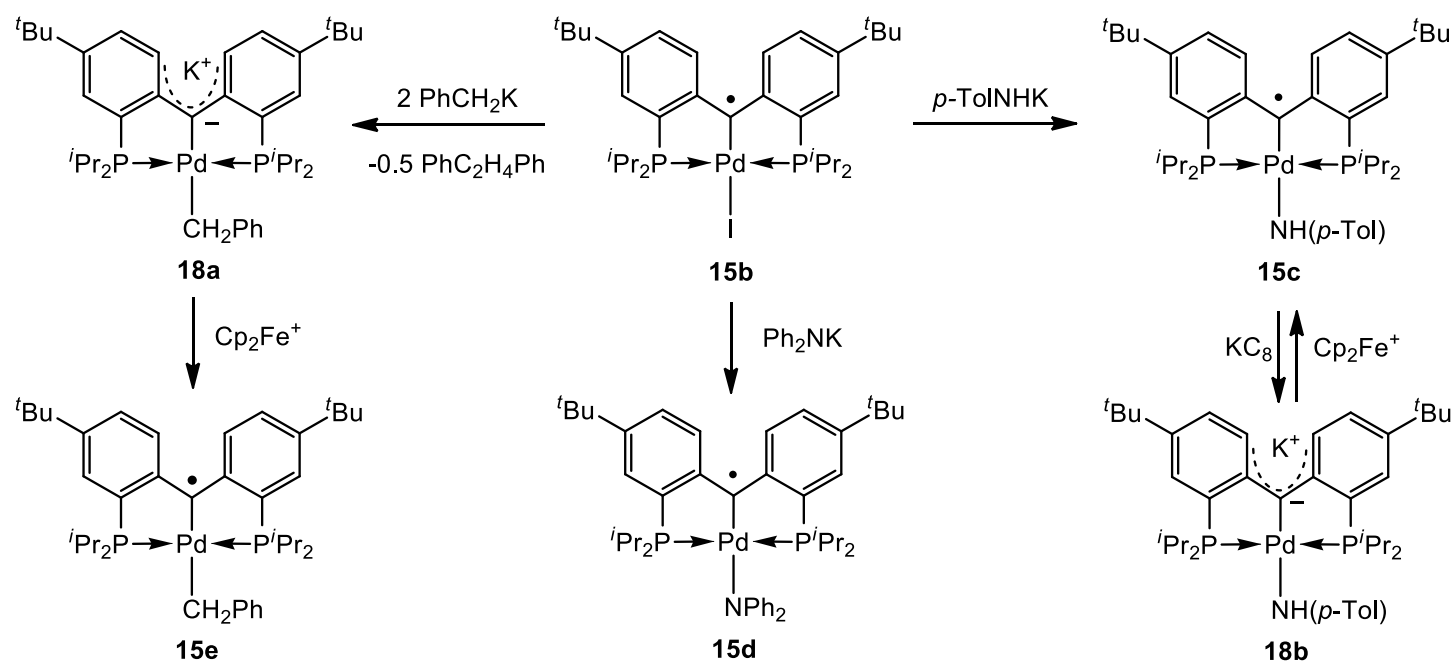

Scheme 19. Unprecedented heterobimetallic palladium-potassium alkylidene complexes generated from the radical carbene $\mathbf{1 5 b}$.

\subsection{Platinum}

Our reports of 2012 and 2015 on the characterization and reactivity of a cationic platinum(II) alkylidene are to the best of our knowledge the first documented studies on a well-defined platinum species of this type. ${ }^{30,48}$ The coordination environment of the metal centre had to be accurately designed to prevent the facile decomposition of the incipient, highly reactive carbene. The bis-platinacyles shown in Scheme 20, based on the bulky phosphines $\mathrm{P}^{i} \mathrm{Pr}_{2} \mathrm{Xyl}$ and $\mathrm{PMeXyl}_{2}$, were treated with a trityl salt in order to remove a hydride from the $\mathrm{Pt}-\mathrm{CH}_{2}$ unit and form a cationic alkylidene complex. Not unexpectedly, the stereochemistry of the starting material was crucial for the success of this strategy, so that only the trans complex of Scheme 20 generated a detectable carbene complex, while the cis one decomposed to unidentified species under analogous reaction conditions. 

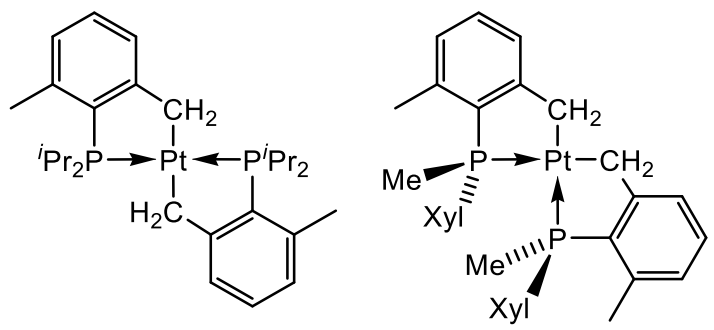

Scheme 20. Bis-platinacycles used for the synthesis of a cationic platinum alkylidene.

All attempts aimed to isolate pure samples of the $\mathrm{Pt}(\mathrm{II})$ alkylidene failed due to decomposition, although the stability of its dichloromethane solutions at low temperature permitted to carry out an extensive investigation on its reactivity towards a variety of organic and inorganic molecules (Scheme 21). The results demonstrated its carbenic nature and its expected electrophilicity. Computational studies were also developed. ${ }^{48}$

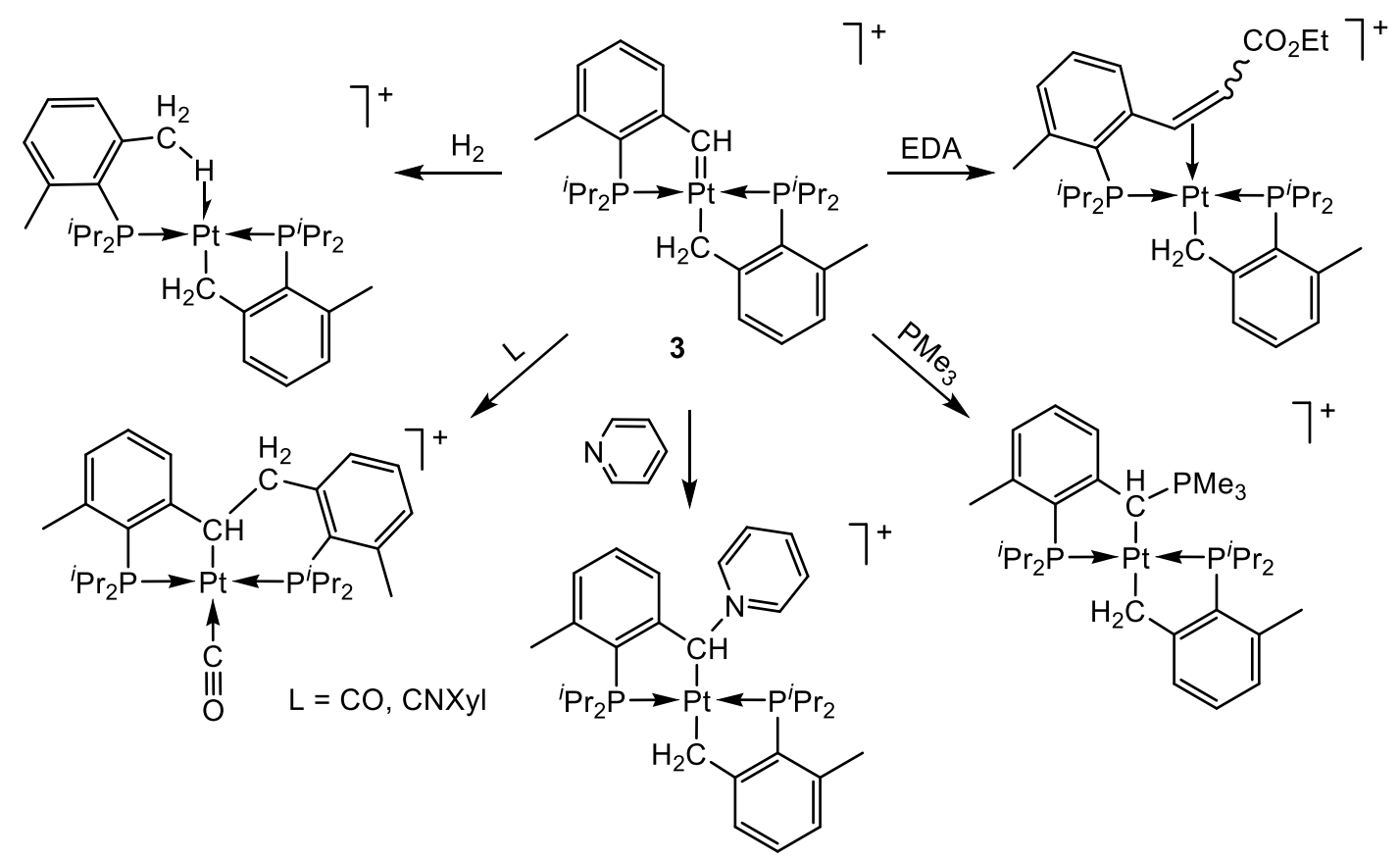

Scheme 21. Reactivity of the Pt(II) alkylidene complex 3 .

Reactions with phosphines and pyridines occurred with C-P and C-N bond formation leading to zwitterionic complexes with the formal positive charge on the group 15 element. In contrast, neutral C donor Lewis bases such as CO or isocyanides, induced a carbene-alkyl coupling in complex $\mathbf{3}$, probably as a consequence of nucleophilic attack of the Pt- $\mathrm{C}_{\text {alkyl }}$ bond onto the electrophilic carbene carbon atom. In accordance with DFT calculations the formation of the new $\mathrm{C}-\mathrm{C}$ bond occurred in a 
pentacoordinated intermediate with trigonal bipyramidal geometry, resulting from $\mathrm{CO}$ coordination to platinum. A typical carbene-carbene coupling reaction was promoted when treating 3 with a diazocompound, resulting in the generation of a $\mathrm{C}=\mathrm{C}$ double bond and formation of the corresponding alkene complex. DFT calculactions were also used to investigate the hydrogenation of complex 3 and revealed that $\mathrm{H}_{2}$ activation would take place at the carbenic carbon.

Although our report of 2012 represented probably the first documented evidence of a well-defined Pt(II) alkylidene, Bercaw and Labinger postulated in 2003 the formation of a $\mathrm{Pt}=\mathrm{CH}_{2}$ terminus in the catalytic alcoholysis of tetramethylsilane promoted by a metal-mediated $\mathrm{C}-\mathrm{H}$ bond activation. ${ }^{49}$ Recently, Templeton and coworkers reported a detailed study on cationic $\operatorname{Pt}(\mathrm{IV})$ complexes $\left[\mathrm{PtTp}^{\prime}(\mathrm{Me})_{2}(=\mathrm{C}(\mathrm{X})(\mathrm{Y})]^{+} \quad\left(\mathrm{Tp}{ }^{\prime}=\right.\right.$ hydrotris(3,5-dimethylpyrazolyl)borate $)$ containing heteroatom stabilized carbene ligands. ${ }^{50}$ Investigation of their chemistry led to the neutral vinyl Tp'Pt(Me $)_{2}\left(\mathrm{CH}=\mathrm{CH}_{2}\right)\left(\right.$ Scheme 22) which upon protonation with $\mathrm{HBAr}_{\mathrm{F}}$ gave a square-planar cationic $\mathrm{Pt}(\mathrm{II})$ complex containing an $\eta^{2}-\mathrm{CH}_{2}=\mathrm{CHCH}_{3}$ olefinic ligand and a $\kappa^{2}$ Tp' ligand protonated at one of the pyrazolyl arms. Evidently, the olefinic ligand resulted from a $\mathrm{C}-\mathrm{C}$ bond formation reaction implicating one of the $\mathrm{Pt}$ Me bonds. Low temperature NMR studies $\left(-80^{\circ} \mathrm{C}\right)$ evinced the formation of a shortlived ethylidene intermediate, $\left[\mathrm{Tp}{ }^{\prime} \mathrm{Pt}(\mathrm{Me})_{2}(=\mathrm{C}(\mathrm{H}) \mathrm{Me})\right]^{+}(\mathbf{1 9})$, which was characterized by NMR methods. The carbene carbon atom resonates at the striking $\delta$ value of 500 ppm, seemingly the most deshielded carbene resonance observed, and features a ${ }^{1} J_{\mathrm{CH}}$ value of $165 \mathrm{~Hz}$, consistent with $s p^{2}{ }^{1} J_{\mathrm{CH}}$ couplings. The somewhat related carbene $\left[\mathrm{Tp} ' \mathrm{Pt}(\mathrm{Me})_{2}(=\mathrm{C}(\mathrm{OMe})(\mathrm{Me})]^{+}\right.$has a carbene resonance at $264 \mathrm{ppm}$, which implies a shift of over $240 \mathrm{ppm}$ relative to the analogous ethylidene complex. The unusual $\Delta \delta$ value observed was attributed to the cationic character of the carbene carbon and to attenuated $\pi$ backbonding from the $\mathrm{Pt}(\mathrm{IV})$ centre.

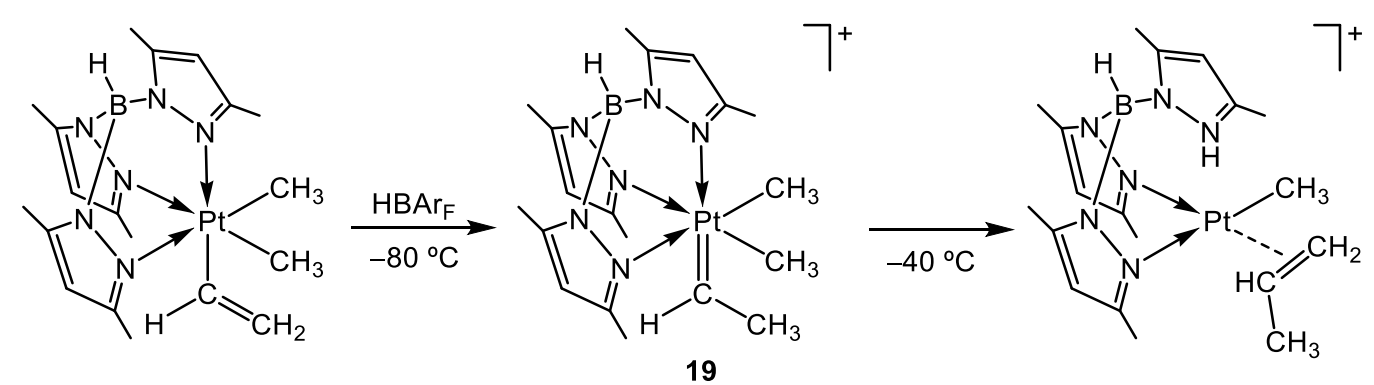

Scheme 22. Generation and rearrangement of Templeton's Pt(IV) alkylidene 19. 
The first structurally characterized Pt alkylidene, 20, was described at the beginning of the current year by Iluc and Barret, in conjunction with the already mentioned lighter congener of palladium, 11 (Scheme 11). ${ }^{40}$

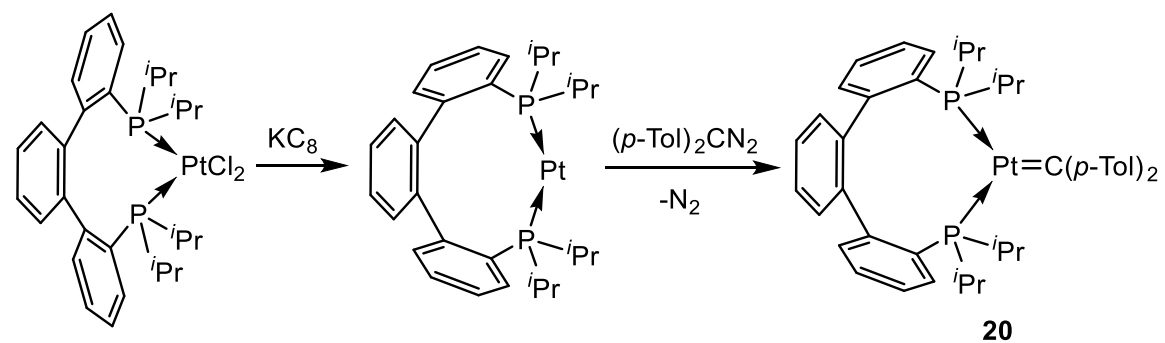

Scheme 23. Synthesis of the Pt(II) alkylidene 20.

The ancillary ligand of choice is once again a sterically demanding diphoshine, now consisting of two $\mathrm{P} \mathrm{Pr}_{2}$ units linked by a terphenyl diradical. The ligand is highly flexible and adapts readily to both cis and trans coordination geometries, such that it is capable to encompass $\mathrm{P}-\mathrm{M}-\mathrm{P}$ angles in the wide range of $c a .99$ to $165^{\circ}$. The elasticity of the terphenyl-bridged diphosphine plays a crucial role in the synthetic strategy employed (Scheme 23) that involves transoid and cisoid complexes (e.g. cis- $\mathrm{PtCl}_{2}\left(\mathrm{P}^{\wedge} \mathrm{P}\right)$ with $\mathrm{P}-\mathrm{Pt}-\mathrm{P}=98.84(2)^{\mathrm{o}}$; trans- $\mathrm{Pt}\left(\mathrm{P}^{\wedge} \mathrm{P}\right), \mathrm{P}-\mathrm{Pt}-\mathrm{P}=153.95(12)^{\circ}$ and the tricoordinate $\left.\mathrm{Pt}\left(=\mathrm{C}(p-\mathrm{Tol})_{2}\right)\left(\mathrm{P}^{\wedge} \mathrm{P}\right), \mathrm{P}-\mathrm{Pt}-\mathrm{P}=105.23(3)^{\circ}\right)$. Similarly to the palladium analogue, the target alkylidene was generated from the two-coordinate $\mathrm{Pt}\left(\mathrm{P}^{\wedge} \mathrm{P}\right)$ platinum $(0)$ complex and $\operatorname{bis}(p$-tolyl)diazomethane. Interestingly, the analogous reaction between the diazomethane reagent and $\mathrm{Pt}\left(\mathrm{Cy}_{3}\right)_{2}$ afforded only the corresponding azine ( $p$ $\mathrm{Tol})_{2}\left(\mathrm{C}=\mathrm{N}-\mathrm{N}=\mathrm{C}(p-\mathrm{Tol})_{2}\right.$ and unaltered $\mathrm{Pt}\left(\mathrm{PCy}_{3}\right)_{2}$, suggesting the generation of catalytic, albeit spectroscopically undetectable, amounts of the alkylidene complex. X-ray crystallography and computational studies support a significant $\pi$ character of the platinum-carbene bond, which is additionally endorsed by the observation by NMR spectroscopy of hindered rotation around the $\mathrm{Pt}=\mathrm{C}(p-\mathrm{Tol})_{2}$ bond.

The reactions of the alkylidene complex 20 with $\mathrm{SiH}_{2} \mathrm{Ph}_{2}$ and $\mathrm{CH}_{3} \mathrm{I}$ were also investigated. The first occurred with formal insertion of the carbene ligand into one of the $\mathrm{Si}-\mathrm{H}$ bonds of the silane, followed by oxidative addition of a second equivalent of $\mathrm{SiH}_{2} \mathrm{Ph}_{2}$ to the resulting $\mathrm{Pt}\left(\mathrm{P}^{\wedge} \mathrm{P}\right)$ complex (Scheme 24 , a). As for the second reaction, it is possible that methyl iodide attacks the $\mathrm{Pt}=\mathrm{C}$ bond with formation of an undetected 
iodo-alkyl $\mathrm{Pt}(\mathrm{II})$ complex that could undergo $\beta$-hydrogen elimination yielding the observed products (Scheme 24, b).
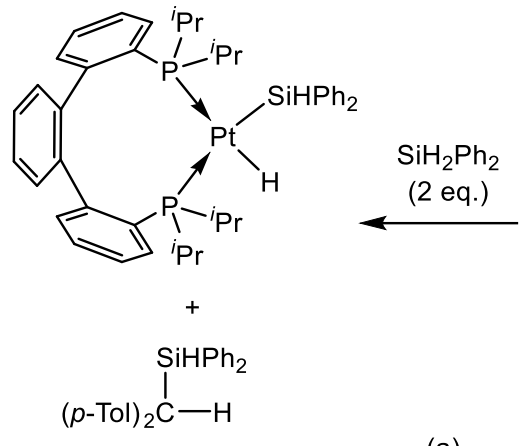

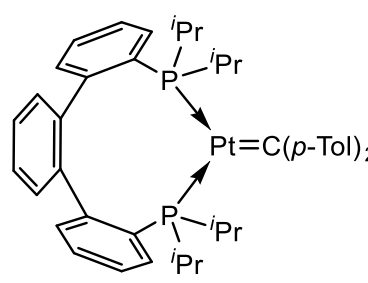

20

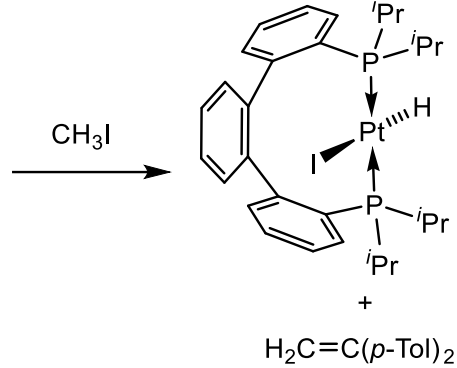

(b)

Scheme 24. Reactions of Pt alkylidene 20 with iodomethane and diphenylsilane.

Interestingly, theoretical investigations support a significant $\pi$ contribution to the Pt-C bonding in 20. On the other hand, no comments on the oxidation state of the metal are provided.

\section{Group 11 metals}

Growing interest in copper catalyzed cyclopropanation reactions gave in the early 2000s a strong impetus to academic investigations on group 11 metal alkylidenes. ${ }^{51}$ To the best of our knowledge, the first report on a spectroscopically detected copper(I) nonheteroatom stabilized alkylidene dates back to 2001, only one year before Hillhouse's first publication on the related nickel complex. In this contribution, Straub and Hofmann used an "extremely basic, sterically demanding, and highly symmetric iminophosphanamide ligand" to stabilize a $\mathrm{Cu}=\mathrm{C}(\mathrm{Ph})\left(\mathrm{CO}_{2} \mathrm{Me}\right)$ fragment, taking advantage of the enhanced metal-to-ligand $\pi$ backdonation and the steric protection provided by the NPN ligand (Scheme 25). ${ }^{52}$

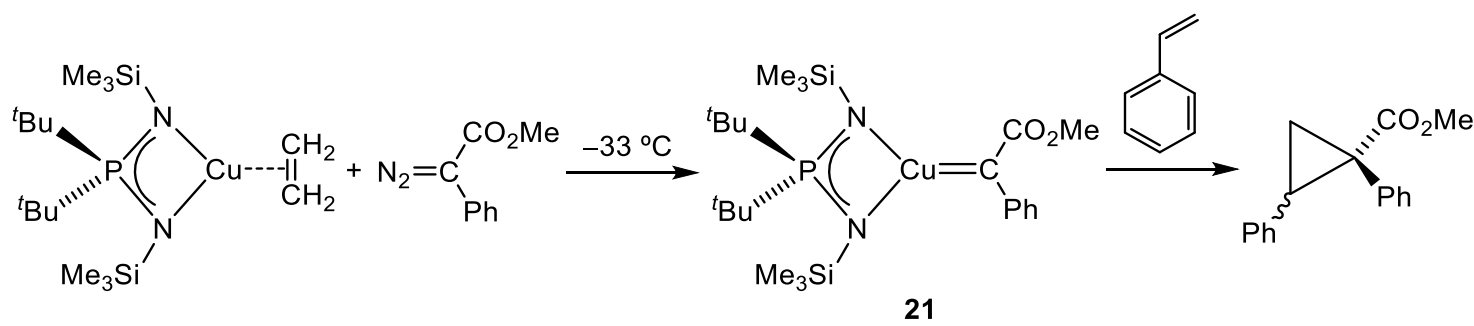


Scheme 25. Generation of the first spectroscopically detected alkylidene complex of $\mathrm{Cu}(\mathrm{I}), \mathbf{2 1}$, and its reaction with styrene.

Actually, complex 21 has a limited stability and survives in solution only at low temperatures in the presence of the starting materials. Nevertheless its carbenic structure was undoubtedly corroborated by NMR spectroscopy and FAB-MS spectrometry, which provided a ${ }^{13} \mathrm{C}\left\{{ }^{1} \mathrm{H}\right\}$ NMR signal at $229.9 \mathrm{ppm}$ in benzene- $d_{6}$ and a molecular ion with $m / z=531.2$, respectively. The alkylidene complex 21 was described as a Fischertype carbene, i.e. with some $\pi$ acceptor character and electrophilic reactivity. Interestingly, it converted readily styrene into the corresponding cyclopropane derivatives.

Prompted by the outstanding silver(I) catalyzed carbene insertion into $\mathrm{C}-\mathrm{H}$ alkane bonds reported by Pérez et al. in $2011,{ }^{53}$ Straub and his group isolated in 2015 the first $\operatorname{Ag}(\mathrm{I})$ alkylidene complex. ${ }^{54}$ This was made possible by the use of the extremely bulky N-heterocyclic carbene IPr**, as the ancillary ligand (Scheme 26).

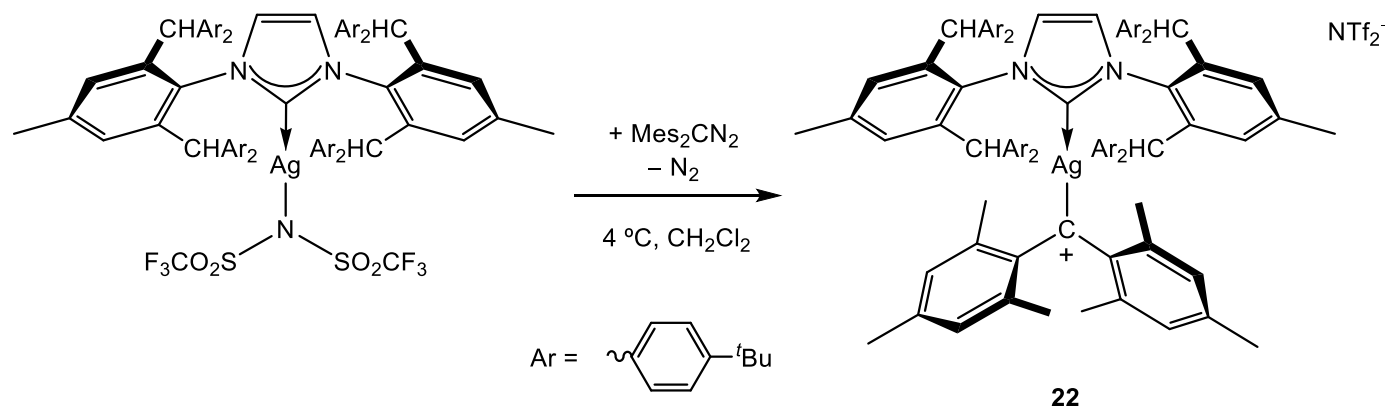

Scheme 26. Synthesis of Straub's silver alkylidene, 22.

The choice to represent complex $\mathbf{2 2}$ as a metal-bonded carbocation is justified by a series of spectroscopic, theoretical, and structural data, which assign negligible metalto-carbon $\pi$ contribution to the silver-carbene bond. This issue will be discussed in more detail in ensuing sections.

Four research groups, independently and almost at the same time, reported in 2014 the first examples of structurally characterized gold(I) alkylidenes that lack direct heteroatom stabilization. ${ }^{55-58}$ Besides, the same year an allylic gold(I) cation was identified by NMR spectroscopy as a reaction intermediate in the rearrangement of 1alkenyl-2-alkynylcyclopropanes. ${ }^{59}$ In this introductory discussion on group 11 metal alkylidenes, it seems reasonable to focus only on one of these findings. Chronologically 
it was the first that appeared in the literature, besides it fits completely in the scope of this review. This gold(I) derivative was prepared by Fürstner and Seidel via a formal transmetalation reaction in which the carbene initially linked to a $\left[\mathrm{Cr}(\mathrm{CO})_{5}\right]$ fragment was transferred to the cation $\left[\mathrm{Au}\left(\mathrm{PCy}_{3}\right)\right]^{+}($Scheme 27$) .{ }^{55}$

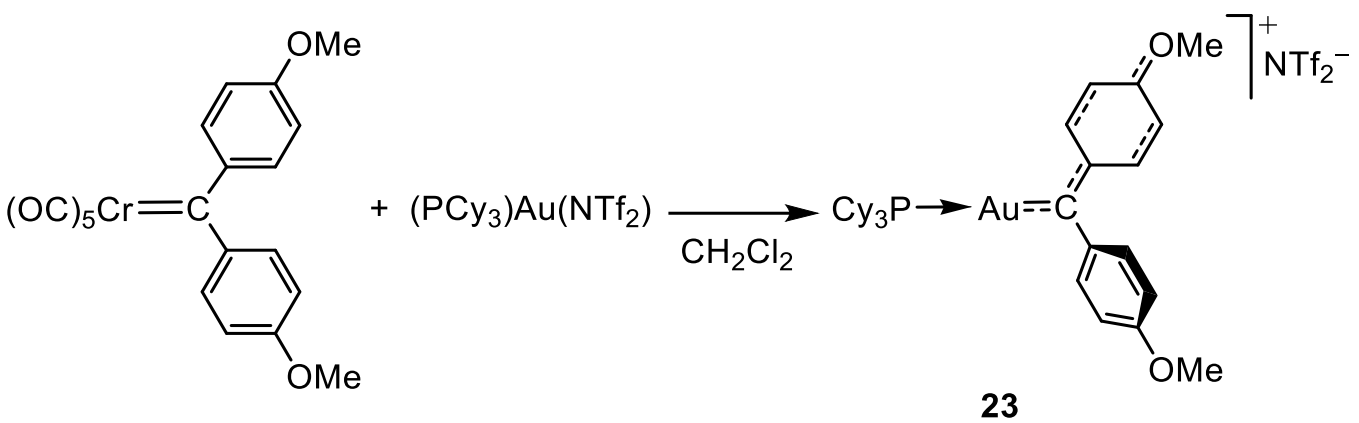

Scheme 27. The gold(I) alkylidene (23) prepared by Fürstner in 2014.

Despite the fact that the oxygen atoms in the substituents of the alkylidene ligand are not directly bound to the divalent carbon atom, their role in the stabilization of the final complex is crucial. In fact, using the simple $\mathrm{Ph}_{2} \mathrm{C}=\mathrm{Cr}(\mathrm{CO})_{5}$ as the carbene source, the reaction stopped at a bimetallic $\mathrm{Au}-\mathrm{Cr}$ compound, which decomposed at room temperature. Fürstner affirms that complex $\mathbf{2 3}$ is to be included in the class of carbenoids, as it contains a formal positive charge and a carbon-metal bond at the same site. The double bond character in this species was suggested to be minimal based on structural data. Thus, the coplanarity of one of the anisyl rings with the Au-C linkage and the correspondingly shortened $\mathrm{C}_{\text {anisyl- }} \mathrm{C}_{\text {carbene separation ( }}$. $1.43 \AA$ ) point to the involvement of the $p$ orbital of the carbenic carbon atom in $\pi$ interactions with the aromatic ring and not, or to a negligible extent, with the metal.

\subsection{Copper}

As mentioned above, pioneering work of the group of Hofmann demonstrated that isolation of stable non-heteroatom stabilized copper alkylidenes is possible. ${ }^{52}$ Seven years later the same research group provided deeper insights into the original system with two further articles on $\mathrm{Cu}(\mathrm{I})$ carbenes stabilized by the bulky bisiminophosphanamide $\mathrm{But}_{2} \mathrm{P}\left(\mathrm{NSiMe}_{3}\right)_{2}{ }^{-60 \mathrm{a}}$ Increased stability of the alkylidene structure was gained by introducing an aryl substituent at the carbene carbon atom instead of the ester group of complex 21. This modification permitted the detection of the diphenylcarbene complex in a steady $35 \%$ concentration with respect to the alkene 
complex used as precursor. Nevertheless, attempts to isolate the target compound in the solid state induced the unavoidable reaction between the two species, generating an unusual carbene-bridged dicopper compound (Scheme 28, a). By contrast, as elegantly explained by the authors, a more stable copper(I) alkylidene was prepared by increasing the $\pi$ backdonation component of the $\mathrm{Cu}=\mathrm{C}$ bond, which was accomplished using $p$ nitrophenyl substituents at the carbenic carbon atom (Scheme 28, b). Complex 24 was isolated in the solid state and characterized by X-ray diffraction analysis. Interestingly, this different bonding situation is reflected not only in the reduced reactivity of the compound but also in its NMR characteristics. Thus, metal-to-carbon $\pi$ backbonding provokes deshielding of the ${ }^{31} \mathrm{P}$ nucleus of the NPN ligand in $\mathbf{2 4}$ compared to $\mathbf{2 1}$, as a consequence of increased electron-density transfer from the $\mathrm{N}_{\text {amido }}$ atoms to the metal. Moreover, ${ }^{31} \mathrm{P}^{29} \mathrm{Si}$ NMR coupling constants ${ }^{61}$ vary in accordance with Bent's rule, ${ }^{62}$ which predicts that the $s$-character of phosphorus and silicon in $\mathrm{Si}-\mathrm{N}$ and P-N bonds would decrease when decreasing the net charge at the nitrogen atom owing to coordination of the electron-withdrawing nitrocarbene to copper.

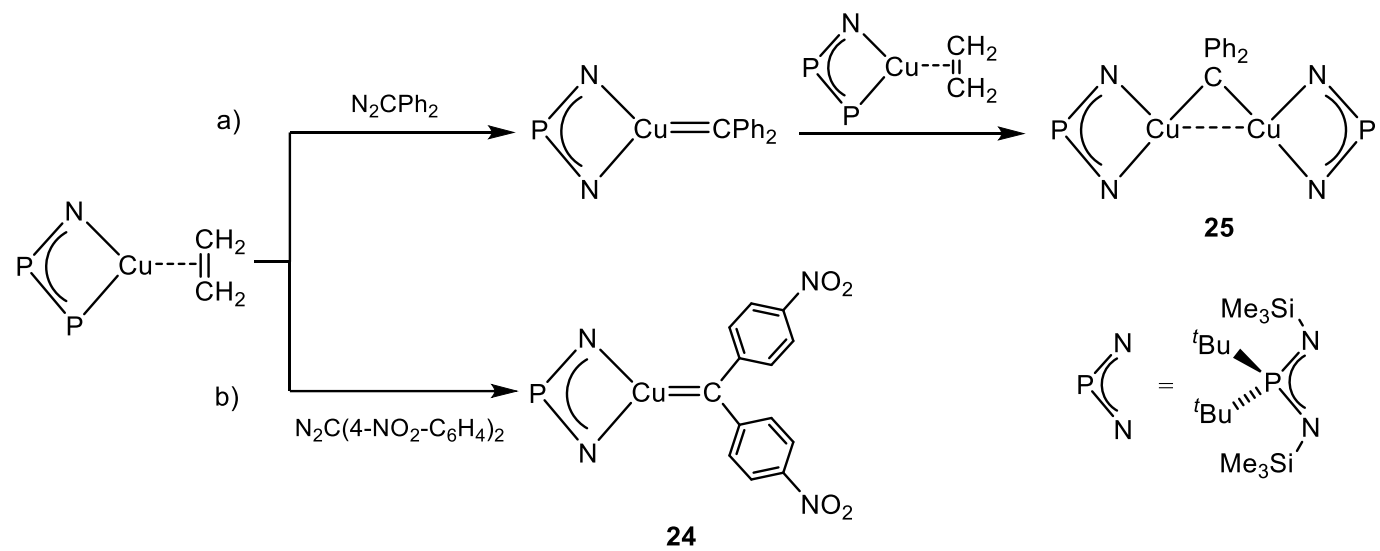

Scheme 28. Synthesis of mono- and dinuclear diarylsubsituted copper alkylidenes described by Hofmann.

Hofmann also found that complex $\mathbf{2 4}$ reacts with styrene to yield the expected cyclopropane, whereas the dimeric complex 25 does not. These findings suggest that terminal alkylidenes act as : $\mathrm{CR}_{2}$ transfer agents in copper catalyzed cyclopropanation of olefins with diazocompounds, and rule out carbene-bridged dinuclear complexes as keyintermediates. In the same year, Hofmann and collaborators succeeded in the preparation of a series of stable $\alpha$-carbonyl $\mathrm{Cu}(\mathrm{I})$ alkylidenes of general formula $(\mathrm{NPN}) \mathrm{Cu}=\mathrm{C}\left(\mathrm{COOR}{ }_{1}\right)\left(p-\mathrm{X}-\mathrm{C}_{6} \mathrm{H}_{4}\right)$, which were subjected to kinetic, spectroscopic and structural studies. ${ }^{60 \mathrm{~b}}$ For instance, measurement of the aryl group rotation barrier around 
the $\mathrm{C}_{\text {carbene- }} \mathrm{C}_{\text {aryl }}$ axis via NMR for complexes $26\left(\mathrm{R}_{1}={ }^{t} \mathrm{Bu}, \mathrm{X}=\mathrm{OMe}\right), 27\left(\mathrm{R}_{1}=\mathrm{Me}, \mathrm{X}\right.$ $=\mathrm{H}), 27^{\prime}\left(\mathrm{R}_{1}={ }^{t} \mathrm{Bu}, \mathrm{X}=\mathrm{NO}_{2}\right)($ Scheme 29$)$, showed a dramatic dependence on the electronic characteristics of the para substituent $(\mathrm{X})$ in the aromatic ring. Hence, the strongly $p$-donor OMe group raises the barrier by about $13 \mathrm{~kJ} / \mathrm{mol}$ compared with a simple $\mathrm{H}$, while the electron-withdrawing $\mathrm{NO}_{2}$ substituent acts in the opposite direction reducing considerably its value. Likewise, the rotation of the alkylidene unit around the $\mathrm{Cu}-\mathrm{C}$ axis is hindered by the nitro group (Table 1). All these observations are in agreement with the variations of bond orders expected for the $\mathrm{Cu}-\mathrm{C}_{\text {carbene }}$ and $\mathrm{C}_{\text {aryl- }}$ $\mathrm{C}_{\text {carbene linkages. }}$<smiles>CCCCOC(=O)c1ccc(OC)cc1</smiles>

26<smiles>CC(=O)/C(=C1/N2N=[PH]12)c1ccccc1</smiles>

27<smiles>CCCCOC(=O)c1ccc([N+](=O)[O-])cc1</smiles>

27'

Scheme 29. Hofmann's $\alpha$-carbonyl Cu(I) alkylidenes 26, 27, 27'.

Table 1. Rotation barriers $(\mathrm{kJ} / \mathrm{mol})$ of the aryl group and the carbene ligand determined by NMR spectroscopy for complexes $\mathbf{2 4}, \mathbf{2 7}$, and $\mathbf{2 7}$ '.

\begin{tabular}{|c|c|c|}
\hline Complex & $\mathrm{C}_{\text {carbene- }} \mathrm{C}_{\text {arene }}$ & $\mathrm{Cu}=\mathrm{C}_{\text {carbene }}$ \\
\hline $\mathbf{2 6}$ & $49.8 \pm 0.9$ & $68.9 \pm 1.9$ \\
\hline $\mathbf{2 7}$ & $36.8 \pm 3.0$ & $>60$ \\
\hline $\mathbf{2 7}$ & fast on NMR time scale & $>81$ \\
\hline
\end{tabular}

A final observation stemming from the very relevant work of the Hofmann group concerns with DFT studies on complex $(\mathrm{NPN}) \mathrm{Cu}=\mathrm{C}(\mathrm{COOMe})\left(p-\mathrm{OMe}-\mathrm{C}_{6} \mathrm{H}_{4}\right){ }^{60 \mathrm{~b}}$ Computation revealed that the $\mathrm{Cu}-\mathrm{C} \pi$ bonding (HOMO-1) is predominantly located on the metal atom with a Mulliken charge close to zero, thus assigning a clear Fischer-type character to the complex.

A nice comparison between mononuclear terminal and dinuclear bridged copper(I) alkylidenes was provided by Warren and Dai in $2004,{ }^{63}$ once more in close relationship with catalytic studies on alkene cyclopropanation. 


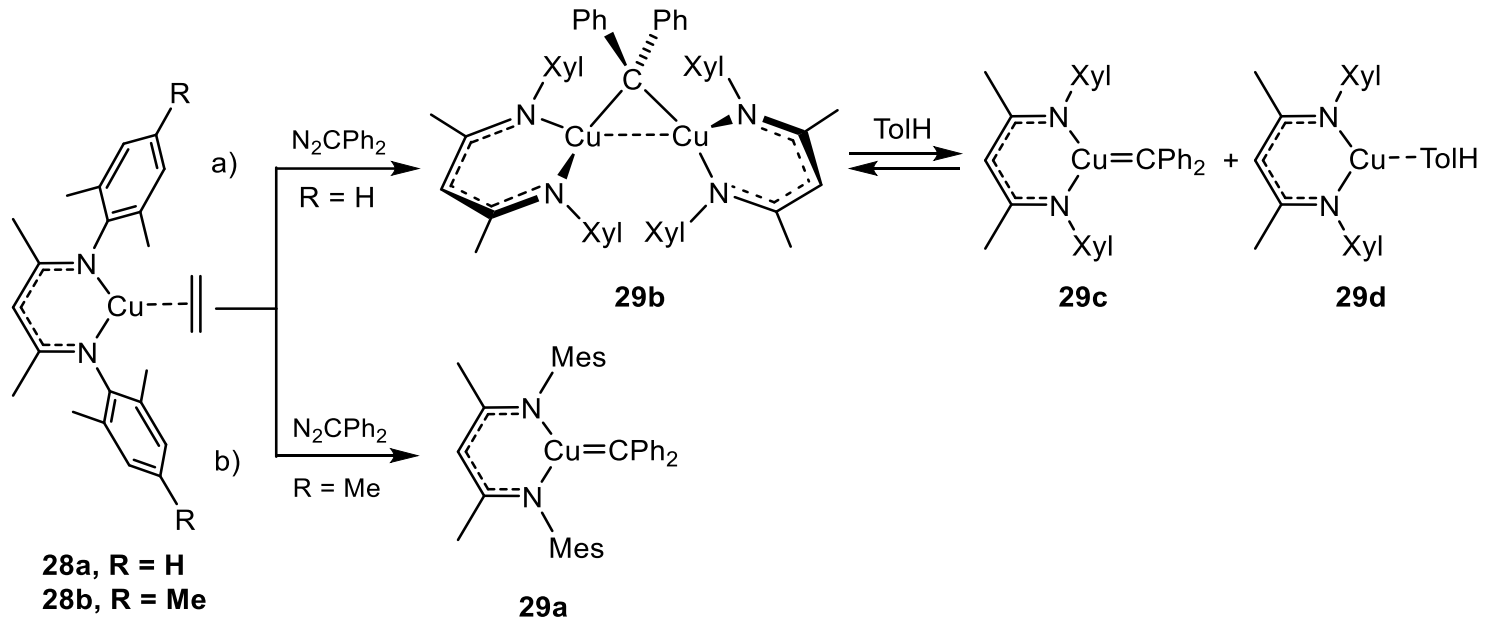

Scheme 30. Synthesis of mono- and dinuclear diarylsubsituted copper alkylidenes described by Warren.

Sterically protected $\mathrm{Cu}(\mathrm{I})$ ethylene diketiminates, $\mathbf{2 8 a}$ and $\mathbf{2 8 b}$, were used as starting materials for the synthesis of alkylidenes 29a and 29b (Scheme 30). As shown in Scheme 30, a slight modification of the molecular structure of the N,N anionic ligand, i.e. the introduction of a methyl group in the para position of the aryl rings, made possible the selective formation and isolation of the terminal alkylidene complex 29a, which is the first structurally characterized representative of this class. Noteworthy, in the presence of the smaller, xylyl-substituted diketiminate, the bimetallic complex 29b formed selectively and subsequently underwent fast dissociation equilibrium in toluene solution giving rise to the mononuclear alkylidene 29c and the toluene adduct 29d. Thermodynamic parameters for the equilibrium shown in Scheme 30 were calculated by variable-temperature NMR experiments and revealed that the reaction is slightly endothermic.

Aiming to add information on the mechanism of olefin cylclopropanation, dicopper carbene 29b was reacted (Scheme 31): a) with styrene, obtaining the expected cyclopropane and the alkene complex 29e; and b) with diphenyldiazomethane, obtaining the diazine $\mathrm{Ph}_{2} \mathrm{C}=\mathrm{N}-\mathrm{N}=\mathrm{CPh}_{2}$ in low yield and non-identified copper species (no comments are provided about this point). Thermal decomposition of $\mathbf{2 9} \mathbf{b}$ at room temperature in solution gave tetraphenylethylene and the solvent adduct 29d. Additionally, several reactions of a slightly modified version of the bimetallic species 29b with nucleophiles were reported in 2005, indicating its ability to act as carbene transfer reagent. ${ }^{64}$ 


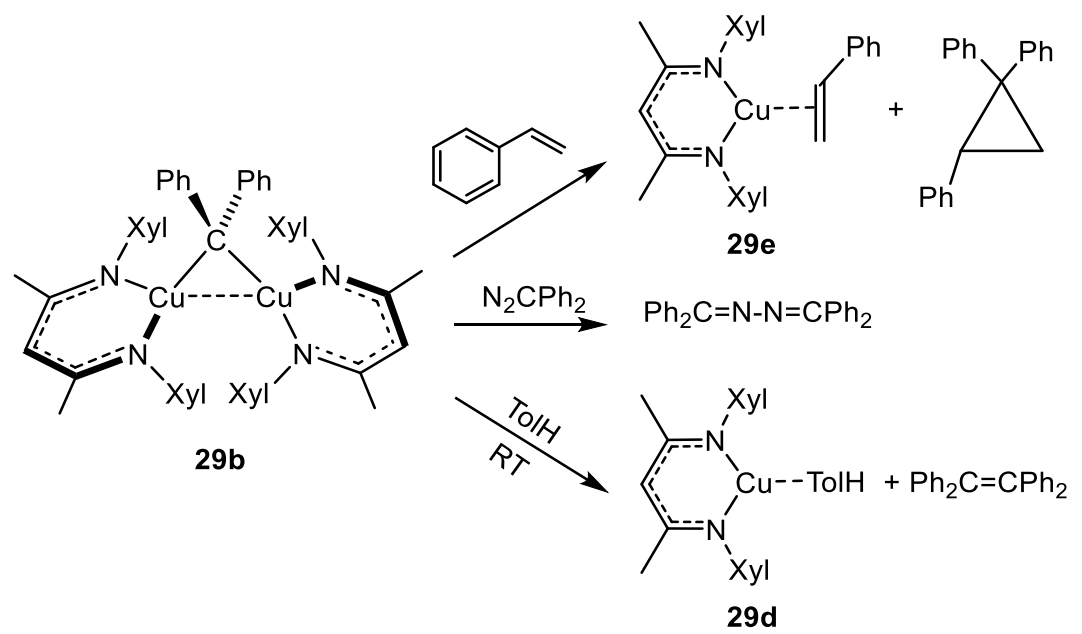

Scheme 31. Reactivity of the dicopper carbene complex 29b.

Moreover, reactivity experiments were performed for the terminal alkylidene 29a, as summarized in Scheme 32. Interestingly, the dinuclear carbene-bridged alkylidene can be obtained by decomposition of the monomer in aromatic solvents.

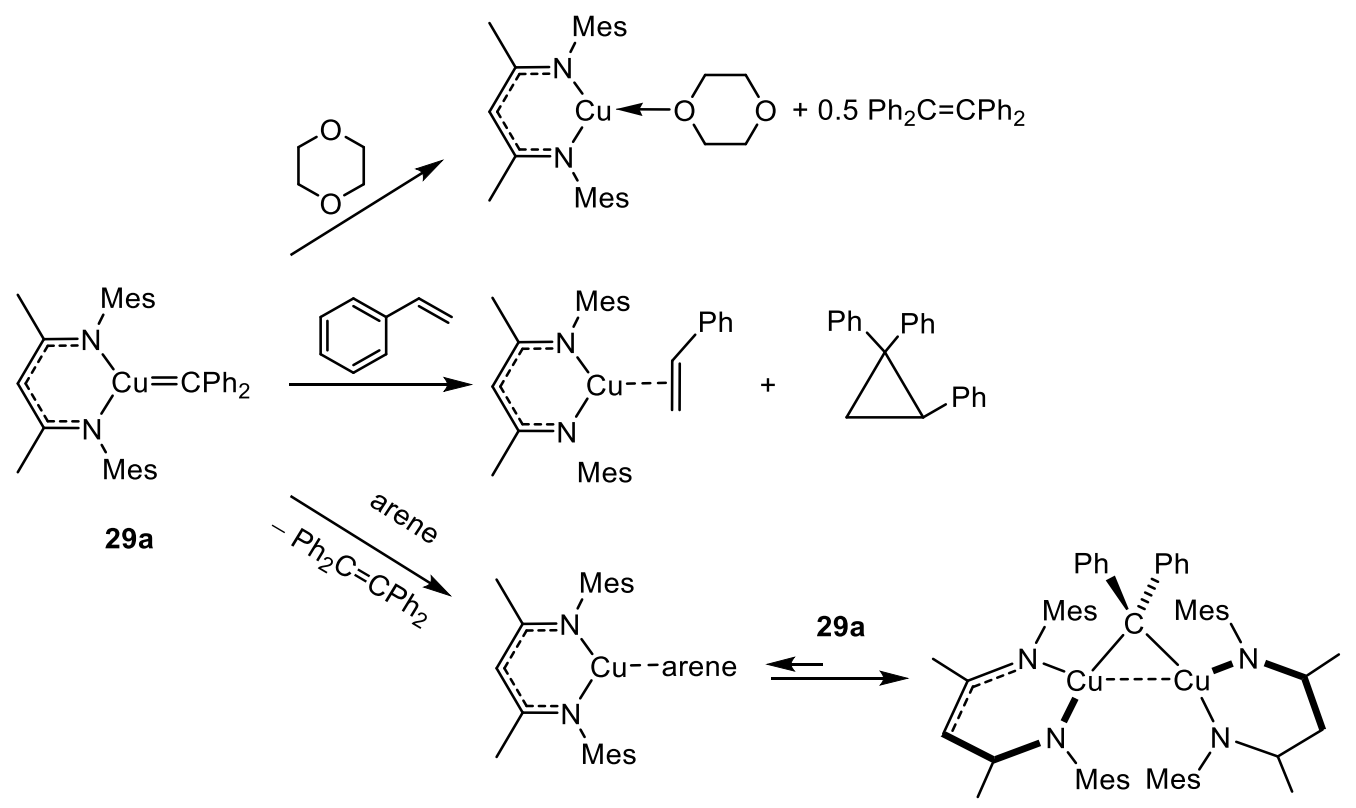

Scheme 32. Reactivity of the copper alkylidene 29a.

Before closing this discussion, theoretical calculations aimed to understand the bonding in Warren's alkylidenes deserve a last comment. The diphenylcarbene moiety in the bimetallic complex is essentially perpendicular to the planes containing the sixmembered $\mathrm{Cu}(\mathrm{I})$-diketiminate cycles, maximizing in this way backbonding from the metal $d$ orbitals to the empty $p$ orbital of the $\mathrm{CPh}_{2}$ carbon atom. Moreover, comparison 
with the mononuclear terminal alkylidene 29a reveals a stronger $\pi$ backbonding contribution in the bimetallic species as a consequence of the three-centre, four-electron interaction existing in the $\mathrm{CCu}_{2}$ core.

As described in preliminary form in 2008, Peters and Mankad used a sterically demanding bis(phosphino)borate ligand to generate a terminal $\mathrm{Cu}(\mathrm{I})$ alkylidene, 30 (Scheme 33). ${ }^{65}$ Its limited stability only permitted spectroscopic characterization (NMR, UV-vis) in solution, as decomposition with liberation of tertraphenyl ethylene was observed even at $-30{ }^{\circ} \mathrm{C}$. Complex 30 is produced from the amino derivative $\mathbf{3 1}$ with excess diphenyldiazomethane, with concomitant formation of the unusual azine adduct 32.

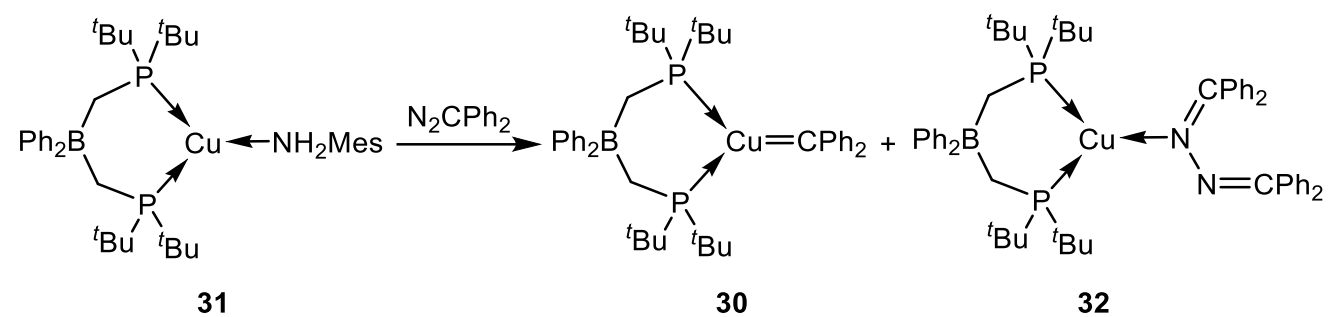

Scheme 33. Generation of the copper alkylidene $\mathbf{3 0}$ characterized by Peters.

The carbenic nature of complex $\mathbf{3 0}$ was further demonstrated by its reaction with carbon monoxide, which yielded selectively the $(\mathrm{PBP}) \mathrm{Cu}(\mathrm{CO})$ carbonyl complex and the ketene $\mathrm{Ph}_{2}=\mathrm{C}=\mathrm{CO}$, that is the product of formal carbene transfer from the metal to CO.

The already mentioned communication by Straub and coworkers on the first isolated silver alkylidene of the $\mathrm{Ag}=\mathrm{CR}_{2}$ type also reported the characterization in solution of its copper analogue, 33 (Scheme 34). ${ }^{54}$ Even under optimized reaction conditions only concentrated solutions of the copper carbene could be obtained, i.e. clean and selective conversion of the substrates was not achieved. Nevertheless, satisfactory NMR, UV-vis, and HR-ESI characterization was provided for complex 33. The original UV-vis and NMR spectroscopic studies performed by Straub on the three isostructural complexes [(IPr**) $\left.\mathrm{M}\left(\mathrm{CPh}_{2}\right)\right](\mathrm{M}=\mathrm{Cu}, \mathrm{Ag}, \mathrm{Au})$, in conjunction with theoretical calculations, offer novel insights into the nature of the bonding in this class of cationic coinage metal alkylidenes. This discussion is postponed to the chapter dedicated to gold, as a final summary. 


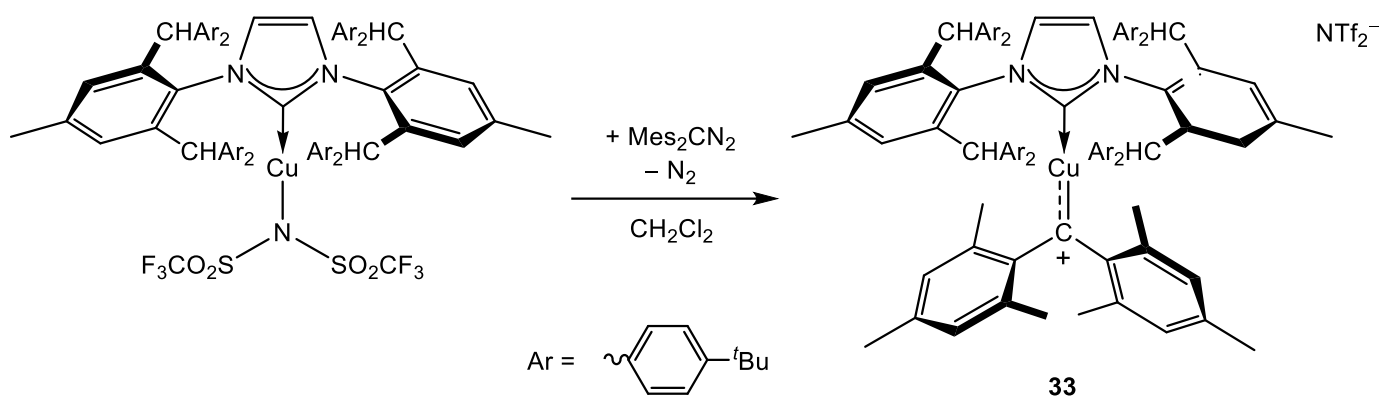

Scheme 34. Synthesis of the copper alkylidene 33.

The last example of this family of complexes appeared very recently in a contribution by Wang and collaborators aimed to isolate possible intermediates generated in the course of catalytic amination of alkynes. ${ }^{66}$ Thus, copper and gold carbenes were obtained in a novel template synthesis in which the metal promoted the cyclization of a sterically demanding $\mathrm{N}$-alkynyl formamidine and its transformation into an alkylidene ligand (Scheme 35). Nevertheless, similarly to its gold congener, the $\mathrm{Cu}(\mathrm{I})$ complex 34a presents a high degree of delocalization owing to the mesoionic imidazolium substituent, which implies that the vinyl mesomeric form shown in Scheme 35 provides a major contribution. Indeed, the double bond character of the C-O linkage is demonstrated by X-ray structural data.
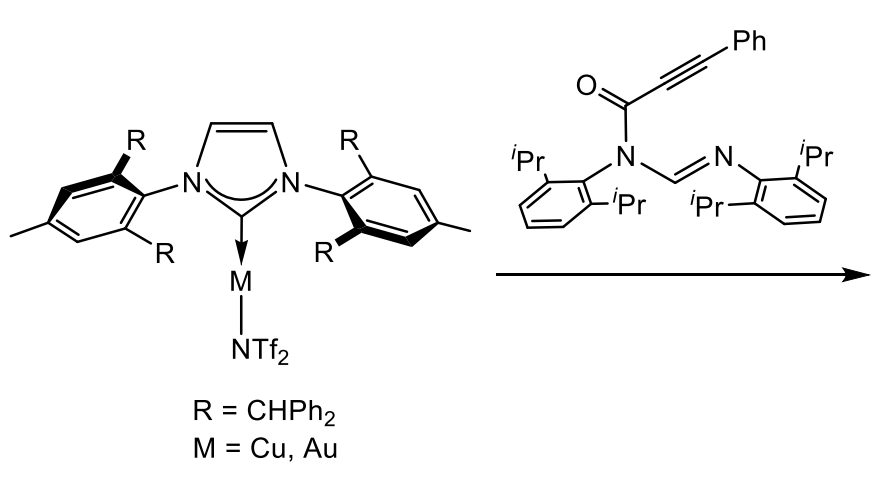

$\mathrm{R}=\mathrm{CHPh}_{2}$$$
\text { Cus Au }
$$

Scheme 35. Synthesis of the imidazolium-stabilized copper and gold alkylidenes 34 .

\subsection{Silver}

In spite of the great number of catalytic organic transformations in which they are supposed to be implied, silver carbene complexes without heteroatom substituents remained a mere hypothesis for decades, as their intrinsic high reactivity made impossible to provide any direct experimental evidence for their formation in the condensed phase. Only very recently, ${ }^{54}$ Straub and collaborators isolated the first 
representative of this class (vide supra). Moreover, they provided satisfactory solution and solid-state characterization despite the impossibility to find a clean synthetic procedure owing to the extreme reactivity and thermal instability of the compound.

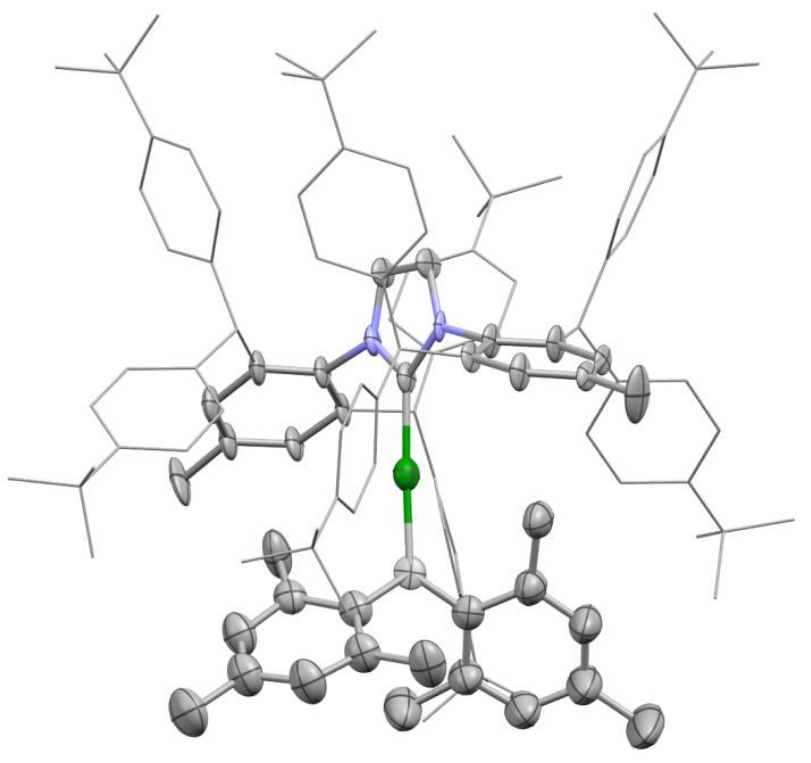

Figure 3. ORTEP plot of the X-ray molecular structure of the silver alkylidene complex (22) reported by Straub et al. in 2015.

The structural and spectroscopic data gathered for this compound deserve some additional comments, aimed to clarify the nature of the $\mathrm{Ag}-\mathrm{CMes}_{2}$ bond. The $\mathrm{Ag}$ CMes2 separation is ca. $6 \mathrm{pm}$ longer than the other metal-carbon bond distance (i.e. Ag$\left.\mathrm{C}\left(\operatorname{IPr}^{* *}\right)\right)$, which reflects the very limited or insignificant backbonding contribution. On the other hand, the negligible resonance stabilization of the divalent carbon in complex 22 is demonstrated by the fact that the mesityl substituents of the alkylidene are twisted out of the NHC-Ag-C plane (see Figure 3). Moreover, the ${ }^{13} \mathrm{C}$ NMR signals due to the Ag-CMes2 carbon appear at very high frequency (332 ppm), consistent with highly reduced metal-to-carbon backdonation. Particularly informative is the comparison between the ${ }^{13} \mathrm{C}$ resonances due to the two different silver-bonded carbon atoms, being the alkylidene one $c a .50 \mathrm{ppm}$ down-field shifted with respect to the other. In addition, Ag-C coupling constants for silver bonded carbons reflect, accordingly to Bent's rule, the bonding situation in complex 22 and in the precursor. To the best of our knowledge, this is the only example of non-heteroatom stabilized silver alkylidene isolated, or even characterized, to date.

\subsection{Gold}


The interest in alkylidene complexes of gold(I) has experienced a rapid and impressive growth in the last years, driven by the great importance of a variety of Au catalyzed organic transformations. Extensive data on well-defined species in the condensed phase were anticipated by Chen and co-workers, ${ }^{67}$ who developed a method for the gas-phase generation of gold carbenes via collision-induced dissociation of ylide precursors (Scheme 36). ${ }^{68}$

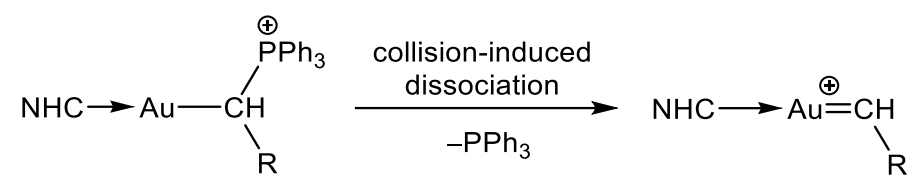

Scheme 36. Gas-phase generation of gold alkylidenes.

Theoretical work by Toste, Goddard and co-workers ${ }^{69}$ offers a useful tool for the estimation of the different contributions to the bonding in gold species of the general formula $\mathrm{LAu}^{\mathrm{I}}\left(\mathrm{CR}_{2}\right)$ depending on the carbene ligand substituents and the ligand $\mathrm{L}$, with special reference to cationic phosphine complexes (Figure 4). Interestingly, the general conclusion is that the overall bond order of gold carbenes is "generally less than or equal to one".

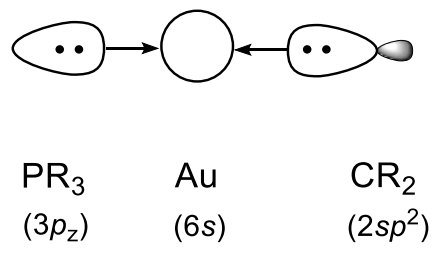

3-centre-4 electron $\sigma$ bond

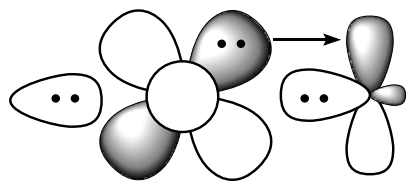

$\mathrm{L}$

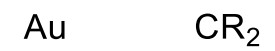

$\left(5 d_{\mathrm{xy}}\right)$

$\left(2 p_{\mathrm{x}}\right)$

Au-C $\pi$ backdonation

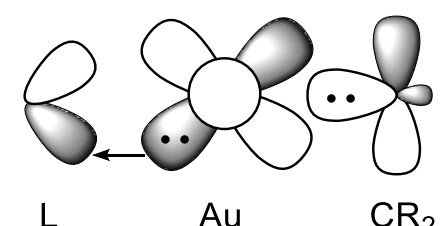

$\left(\sigma_{\mathrm{PR}}{ }^{*}, 3 d_{\mathrm{xy}}\right) \quad\left(5 d_{\mathrm{xy}}\right)$

Au-L $\pi$ backdonation

Figure 4. Bonding in $\left[\left(\mathrm{PR}_{3}\right) \mathrm{Au}\left(\mathrm{CR}_{2}\right)\right]^{+}$, as described by Goddard and Toste. In the schematic representations of the $\pi$ bonds, the orbitals of $\sigma$ symmetry that mainly influence the extent of the interaction are also depicted.

As mentioned above, Fürstner and Seidel succeeded in the solid-state isolation of the first non-heteroarom substituted gold alkylidene (Scheme 27). ${ }^{55}$ Some comments will be dedicated to the synthesis, structural and spectroscopic properties, and reactivity of this compound (Scheme 37). 


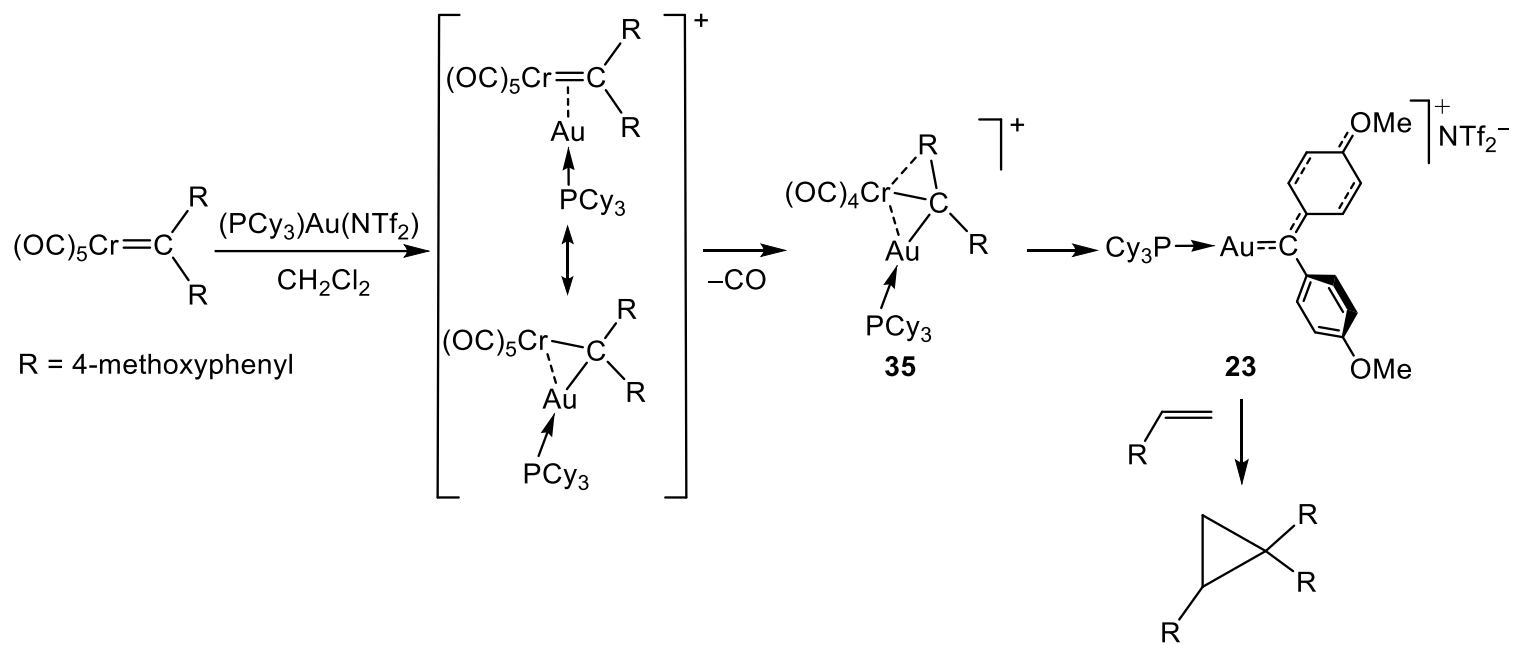

Scheme 37. Synthesis of the bis(p-methoxyphenyl)carbene complex of gold(I), 23, reported by Fürstner and Seidel.

Alkylidene $\mathbf{2 3}$ was generated by transmetallation, along with the bimetallic species $\mathbf{3 5}$ in $c a$. 3:2 ratio. It is moderately stable in the crystalline form even at room temperature and can convert a substituted styrene into the corresponding cyclopropane via formal carbene transfer. To correlate the metal-carbon bond order with structural measurements, the authors compared the Au-C separation in 23 with those found in complexes of the type $[\mathrm{Au}=\mathrm{C}(\mathrm{OMe})(\mathrm{Ar})]^{+}$. Besides, the $\mathrm{C}_{\text {carbene }} \mathrm{C}_{\text {arene }}$ distance in $\mathbf{2 3}$ was contrasted with those observed in a number of species containing the $\mathrm{C}\left(\mathrm{sp}^{2}\right) \mathrm{Ar}_{2}$ unit, such as carbene complexes of ruthenium, benzophenone, and diarylcarbocations. As a consequence of marginal $\pi$ backdonation and strong resonance stabilization promoted by the electron-donating methoxy group, the bond was described as a single Au-C bond. The barrier of rotation around the $\mathrm{C}_{\text {carbene- }} \mathrm{C}_{\text {arene }}$ axis measured at low temperature of only of $c a .35 \mathrm{~kJ} / \mathrm{mol}$ is also in agreement with this perspective. A dirhodium alkylidene source was latterly employed to prepare two further gold complexes of this class. ${ }^{70}$

Somehow related to Fürstner's contribution and reminiscent of Jones' early work on Pt(II), ${ }^{71}$ a relevant study on the synthesis and properties of a gold carbenoid was published by Widenhoefer and Harris in 2014, ${ }^{56}$ who prepared a stable cycloheptatrienylidene complex via hydride abstraction from the parent cycloheptatrienyl derivative. In the absence of heteroatoms linked to the carbene $\mathrm{C}$ atom, it is evident that the involvement of the empty $2 p_{\mathrm{C}}$ orbital in the aromatic $\pi$ system of the tropylium cation plays a crucial role in the stabilization of this species.

Bourissou and collaborators proposed a novel approach to the creation of isolable gold cationic alkylidenes,${ }^{57}$ reasoning that the ancillary ligand $\mathrm{L}$ can be 
specifically designed to enhance the $\pi$ backdonation ability of the $[\mathrm{LAu}]^{+}$moiety, with consequent improvement in the stability of the carbene. This was achieved by using the sterically demanding o-bis(aminophoshino)carborane, DPC, which is able to bend the two-coordinate $(\mathrm{DPC}) \mathrm{Au}^{+}$fragment and raise the energy of the filled $5 d$ orbitals of the metal, therefore promoting the transfer of electron-density to the empty $2 p$ orbital of the carbenic carbon atom. Interestingly, this approach also permitted the isolation of a rare example of cationic $\mathrm{Au}(\mathrm{I})$ carbonyl complex (36), the first of the classical type with a $v(\mathrm{CO})$ of $2113 \mathrm{~cm}^{-1}$ (Scheme 38).

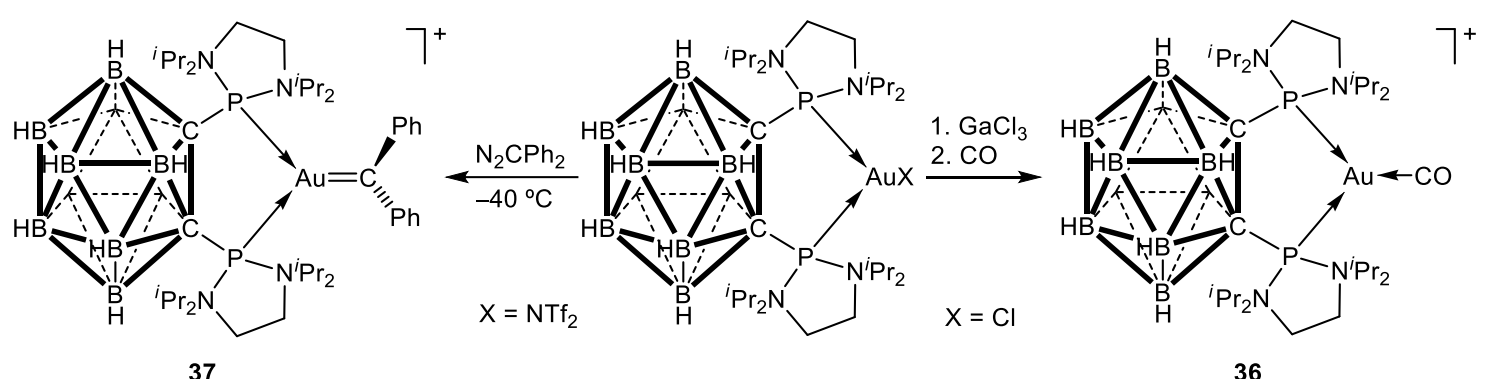

Scheme 38. Synthesis of the stable alkylidene (37) and carbonyl (36) complexes of gold(I) described by Bourissou et al. in 2014.

Some features of the alkylidene complex 37 deserve a brief discussion. The metal centre lies in a highly distorted trigonal-planar environment with P-Au-P angle of ca. $90^{\circ}$, whereas the $\mathrm{CPh}_{2}$ carbon is perfectly planar. The maximization of the $\pi$ backbonding is reflected not only in the short Au-C bond distance of 1.984(4) $\AA$, but also in the orthogonality of the two planes defined by the $\mathrm{PAuP}$ and $\mathrm{CPh}_{2}$ fragments. Moreover, in accordance with the lack of stabilization of the divalent carbon atom by resonance with the phenyl rings, the two aryl groups are twisted from the carbene plane by $c a$. $60^{\circ}$. Finally, DFT calculations offer a picture of the bonding interactions in 37 , assigning to the HOMO a significant character of $\pi$ backbonding involving the $5 d_{\mathrm{xy}}$ orbital of gold and $2 \mathrm{p}^{\pi}$ of carbon. The LUMO coincides basically with the corresponding anti-bonding interaction. A nice comparison with Straub's and Fürstner's systems was also provided.

As already cited, Straub and co-workers were able to generate and characterize the series of isostructural complexes of group 11 of the general formula $\left[\left(\operatorname{IPr}^{* *}\right) \mathrm{M}\left(\mathrm{CMes}_{2}\right)\right] \mathrm{NTf}_{2}(33, \mathrm{M}=\mathrm{Cu} ; \mathbf{2 2}, \mathrm{M}=\mathrm{Ag} ; \mathbf{3 8}, \mathrm{M}=\mathrm{Au})$, which allows for a 
stimulating comparison of the bonding in the three compounds. Structural data are available only for the two heavier congeners, $\mathbf{2 2}$ and $\mathbf{3 8} .{ }^{54,58}$

Table 2. Selected experimental data for group 11 metal alkylidenes $\mathbf{3 3}, \mathbf{2 2}$, and $\mathbf{3 8}$.

\begin{tabular}{|c|c|c|c|}
\hline & $\left(\operatorname{IPr}^{* *}\right) \mathbf{C u}\left(\mathrm{CMes}_{2}\right)$ & $\left(\mathrm{IPr}^{* *}\right) \mathbf{A g}\left(\mathrm{CMes}_{2}\right)$ & $\left(\mathrm{IPr}^{* *}\right) \mathbf{A u}\left(\mathrm{CMes}_{2}\right)$ \\
\hline $\mathbf{3 3}$ & - & $205(2)$ & $201.4(6) \mathrm{pm}$ \\
\hline $\mathrm{M}-\mathrm{CMes} 2$ & - & $199(3)$ & $203.0(6) \mathrm{pm}$ \\
\hline$\lambda(\mathrm{HOMO} \rightarrow \mathrm{LUMO})$ & $730 \mathrm{~nm}$ & $742 \mathrm{~nm}$ & $642 \mathrm{~nm}$ \\
\hline $\mathrm{M}-\mathrm{CMes} \delta\left({ }^{13} \mathrm{C} \mathrm{NMR}\right)$ & $332 \mathrm{ppm}$ & $359.3 \mathrm{ppm}$ & $321.3 \mathrm{ppm}$ \\
\hline $\mathrm{Color}$ & greenish yellow & mint-green & emerald-green \\
\hline
\end{tabular}

In both species the negligible resonance stabilization furnished by the mesityl rings is demonstrated by the non-coplanarity the $\mathrm{M}\left(\mathrm{IPr}^{* *}\right)$ fragment and the $\mathrm{CMes}_{2}$ one. Even though the M-C distances in the two species are almost identical within experimental error, the authors recognized a higher extent of metal-to-alkylidene $\pi$ backbonding in the gold complex than in the silver one based on the differences in the M-CMes 2 and M-C(IPr**) separations. In particular, they reasoned that, in agreement with Bent's rule, in the absence of M-C $\pi$ backdonation, the M-C(IPr**) distance should be shorter than the M-CMes2. This fact is actually observed for silver but not for gold. ${ }^{13} \mathrm{C}$ NMR values for the resonances of the alkylidene carbon nuclei in the three species are correlated to the extent of carbenoid character, concluding that it increases in the order $\mathrm{Au}<<\mathrm{Cu}<\mathrm{Ag} .{ }^{1}$

Comments already made on the copper(I) carbene published by Wang in 2017, apply essentially to its isostructural gold congener (34b, Scheme 34$),{ }^{66}$ which should therefore be considered as an atypical heteroatom-stabilized alkylidene.

Table 3. $\mathrm{M}-\mathrm{CRR}$ ' bond distances and ${ }^{13} \mathrm{C}$ NMR chemical shifts for the carbenic carbon nucleus in the alkylidene complexes discussed in this review.

\begin{tabular}{|c|c|c|c|c|}
\hline Metal & Compound & $\begin{array}{c}\mathrm{M}-\mathrm{CRR}^{\prime} \\
(\AA)\end{array}$ & $\begin{array}{c}{ }^{13} \mathrm{C} \text { NMR } \delta \text { for M-CRR' } \\
(\mathrm{ppm})\end{array}$ & Ref. \\
\hline \multirow{2}{*}{$\mathrm{Ni}$} & $\mathbf{1}$ & $1.836(2)$ & 222 & 28 \\
\cline { 2 - 5 } & $\mathbf{6 a}$ & $1.908(5)$ & 182 & 33 \\
\hline
\end{tabular}

\footnotetext{
${ }^{1}$ We note that Straub used the term "carbenoid" in contrast to "carbenium" and "carbene", see reference 58.
} 


\begin{tabular}{|c|c|c|c|c|}
\hline & $6 \mathbf{b}$ & $1.927(4)$ & - & 33 \\
\hline & $7 a$ & $1.793(3)$ & 206 & 35 \\
\hline & $7 b$ & $1.797(3)$ & 216 & 35 \\
\hline \multirow{12}{*}{$\mathrm{Pd}$} & 2 & $1.978(7)$ & 313 & 29 \\
\hline & 10 & $1.999(4)$ & 190 & 39 \\
\hline & 11 & - & 296 & 40 \\
\hline & $12 \mathbf{a}$ & $\begin{array}{l}2.086(4) \\
2.076(1)\end{array}$ & - & 41 \\
\hline & $12 b$ & $2.076(3)$ & 136 & 42 \\
\hline & $15 a$ & $\begin{array}{l}2.020(3) \\
2.005(2)\end{array}$ & - & 45 \\
\hline & $15 b$ & $2.022(3)$ & - & 46 \\
\hline & 17 & $1.968(3)$ & 284 & 46 \\
\hline & $15 c$ & $2.019(2)$ & - & 47 \\
\hline & 15d & $2.024(2)$ & - & 47 \\
\hline & 18a & $2.095(2)$ & - & 47 \\
\hline & $18 b$ & $2.043(2)$ & - & 47 \\
\hline \multirow{3}{*}{$\mathrm{Pt}$} & 3 & - & 209 & 30 \\
\hline & 19 & - & 500 & 50 \\
\hline & 20 & $1.942(3)$ & 263 & 40 \\
\hline \multirow{6}{*}{$\mathrm{Cu}$} & 21 & - & 230 & 52 \\
\hline & 24 & $1.832(2)$ & 240 & $60 \mathrm{a}$ \\
\hline & $26^{a}$ & $1.822(4)^{a}$ & $\sim 230^{b}$ & $60 \mathrm{~b}$ \\
\hline & 29a & $1.834(3)$ & 253 & 63 \\
\hline & 30 & - & 332 & 65 \\
\hline & 33 & - & 332 & 54 \\
\hline $\mathrm{Ag}$ & 22 & $2.05(2)$ & 359 & 54 \\
\hline \multirow{3}{*}{$\mathrm{Au}$} & 23 & $2.039(5)$ & 285 & 55 \\
\hline & 37 & $1.984(4)$ & 316 & 57 \\
\hline & 38 & $2.014(6)$ & 321 & 58 \\
\hline
\end{tabular}

${ }^{a}$ structural data available only for the closely related complex $(\mathrm{NPN}) \mathrm{Cu}=\mathrm{C}[p-$

$\left.\mathrm{OMeC}_{6} \mathrm{H}_{4}\right]\left[\mathrm{CO}_{2}\left\{\mathrm{CH}\left(p-\mathrm{ClC}_{6} \mathrm{H}_{5}\right)_{2}\right\}\right] ;{ }^{b}$ coupling constants available for several complexes of the same type.

\section{Summary and Perspectives}


As we attempted to demonstrate in this review, complexes of groups 10 and 11 metals with non-heteroatom stabilized carbene ligands constitute a young family of organometallic compounds characterized by varied bonding situations, intriguing reactivity, and stimulating spectroscopic and structural features. In light of the scarcity of satisfactorily characterized species existing in the literature, it appears that we are still far from a deep understanding of this class of compounds. For instance, besides the little number of stable non-heteroatom stabilized carbenes of coinage metals, their reactivity is almost unexplored with the exception of a few studies on the function they exert in catalytic cyclopropanation. In spite of the high reactivity of these compounds, recent findings demonstrate that with a suitable choice of ancillary ligands, species with fair thermal stability and therefore quite easy-to-handle can be prepared. ${ }^{57}$ As a final remark, we strongly encourage organometallic and coordination chemists to concentrate further efforts in this research area in view of the intrinsic structural value of these complexes and not least in light of their potential interest in catalysis.

\section{Acknowledgements}

Financial support from the Ministerio de Economía, Industria y Competitividad of the Spanish Government (CTQ2016-75193-P, AEI/FEDER, UE) is gratefully acknowledged.

\section{References}

1. (a) Arduengo, J. A.; Bertrand, G. Chem. Rev. 2009, 109, 3209-3884 (special issue dedicated to carbenes). (b) Crabtree, R. H. J. Organomet. Chem. 2005, 690, 5451; (c) Díez-González, S., Nolan, S.P. Coord. Chem. Rev. 2007, 251, 874.

2. (a) Lavallo, V.; Canac, Y.; Prasang, C.; Donnadieu, B.; Bertrand, G. Angew. Chem. Int. Ed. 2005, 44, 5705; (b) Jazzar, R.; Dewhurst, R. D.; Bourg, J. B.; Donnadieu, B.;Canac, Y.; Bertrand, G. Angew. Chem. Int. Ed. 2007, 46, 2899; (c) Zeng, X.; Frey, D. G.; Kinjo, R.;Donnadieu, B.; Bertrand, G. J. Am. Chem. Soc. 2009, 131, 8690-8696; (d) Chu, J., Munz, D., Jazzar, R., Melaimi, M., Bertrand, G. J. Am. Chem. Soc. 2016, 138, 7884; (e) Roy, S.; Mondal, K. C.;Roesky, H. W. Acc. Chem. Res. 2016, 49, 357.

3. For some leading work, see the following citations and references therein: a) A. Fürstner, P. W. Davies, Angew. Chem. Int. Ed. 2007, 46, 3410; b) A. Fürstner, 
Chem. Soc. Rev. 2009, 38, 3208; c) E. Jiménez- Núñez, A. M. Echavarren, Chem. Rev. 2008, 108, 3326; d) A. M. Echavarren, C. Nevado, Chem Soc. Rev. 2004, 33, 431; e) N. D. Shapiro, F. D. Toste, Synlett 2010, 675; f) D. J. Gorin, F. D. Toste, Nature 2007, 446, 395; g) E. Soriano, J. Marco-Contelles, Acc. Chem Res. 2009, 42, 1026; h) B. Trillo, F. López, S. Montserrat, G. Ujaque, L. Castedo, A. Lledós, J. L. Mascareñas, Chem. Eur. J. 2009, 15, 3336.

4. a) A. Fürstner, H. Szillat, B. Gabor, R. Mynott, J. Am. Chem. Soc. 1998, 120, 8305;

b) A. Fürstner, F. Stelzer, H. Szillat, J. Am. Chem. Soc. 1998, 120, 8305; c) A. Fürstner, H. Szillat, F. Stelzer, J. Am. Chem. Soc. 2000, 122, 6785.

5. a) B. Martín-Matute, C. Nevado, D. J. Cárdenas, A. M. Echavarren, J. Am. Chem. Soc. 1998, 120, 8305; b) A. M. Echavarren, E. Jiménez-Núñez, Top. Catal. 2010, 53, 924; c) V. López-Carrillo, N. Huguet, A. Mosquera, A. M. Echavarren, Chem. Eur. J. 2011, 17, 10972.

6. K. H. Dötz, Metal Carbenes in Organic Synthesis, Springer, 2004.

7. a) Y. Chauvin, Angew. Chem. Int. Ed. 2006, 45, 3740; b) R. R. Schrock, Angew. Chem. Int. Ed. 2006, 45, 3748; c) R. H. Grubbs, Angew. Chem. Int. Ed. 2006, 45, 3760 .

8. a) E. Poverenov, D. Milstein, Chem. Commun. 2007, 3189; b) R. J. Burford, W. E. Piers, M. Parvez, Organometallics 2012, 31, 2949; c) L. E. Doyle, W. E. Piers, J. Borau-Garcia, M. J. Sgro, D. M. Spasyuka, Chem. Sci. 2016, 7, 921; d) J. Yuan, R. P.Hughes, A. L. Rheingold, Dalton Trans. 2015, 44, 19518.

9. R. A. Moss, M. P. Doyle, Contemporary Carbene Chemistry; John Wiley \& Sons, 2014.

10. F. Z. Dörwald (Ed.), Metal Carbenes in Organic Synthesis; Wiley-VCH, Weinheim, Germany, 2008.

11. J. W. Herndon, Coord. Chem. Rev. 2016, 329, 53.

12. a) E. Carmona, M. Paneque, M. L. Poveda, Dalton Trans. 2003, 4022; b) S. Conejero, M. Paneque, M. L. Poveda, L. L. Santos, E. Carmona, Acc. Chem. Res. 2010, 43, 572.

13. a) J. Campos, R. Peloso, M. Brookhart, E. Carmona, Organometallics 2013, 32, 3423; b) J. Campos, E. Carmona, Organometallics 2015, 34, 2212; c) J. Campos, M. F. Espada, J. López-Serrano, E. Carmona, Inorg. Chem. 2013, 52, 6694; d) J. Campos, J. López-Serrano, E. Álvarez, E. Carmona, J. Am. Chem. Soc. 2012, 134, 7165. 
14. M. T. Whited, R. H. Grubbs, Acc. Chem. Res. 2009, 42, 1607.

15. H. Werner, Angew. Chem. Int. Ed. 2010, 49, 4714.

16. a) E. O. Fischer, A. Maasböl, Angew. Chem. Int. Ed. 1964, 3, 580; b) E. O. Fischer, Adv. Organomet. Chem. 1976, 14, 1; b) U. Schubert (ed.), Advances in Metal Carbene Chemistry; Dodrecht, The Netherlands: Kluver Academic Publishers, 1988; c) K. H. Dötz, H. Fischer, P. Hofmann, F. R. Kreissl, U. Schubert, K. Weiss, Transition Metal Carbene Complexes, Verlag Chemie, Weinheim, Germany, 1983.

17. K. Öfele, Angew. Chem. Int. Ed. 1968, 7, 950.

18. a) R. R. Schrock, J. Am. Chem. Soc., 1974, 96, 6796; b) Acc. Chem. Res., 1979, 12, 98.

19. a) A. Aguero, J. A. Osborn, New J. Chem. 1988, 12, 111; b) J. P. Collman, L. S. Hegedus, Principles and Applications of Organotransition Metal Chemistry. University Science Books, Mill Valley, California, 1980.

20. a) P. J. Brothers, W. R. Roper, Chem. Rev. 1988, 88, 1293; b) M. A. Gallop, W. R. Roper, Adv. Organomet. Chem. 1986, 25, 121.

21. a) J. E. Hahn, Progr. Inorg. Chem. 1984 31, 206; b) F. A. Cotton, G. Wilkinson, Advanced Inorganic Chemistry, $5^{\text {th }}$ Edition, John Wiley \& Sons, New York, 1988, p. 1139.

22. a) M. Bochmann, Organometallics and Catalysis. An Introduction, University Press, Oxford, 2014, p. 275; b) C. Elschenbroich, Organometallics, Wiley-VCH, Weinheim, 2006.

23. a) R. J. Goddard, R. Hoffmann, E. D. Jemmis, J. Am. Chem. Soc. 1980, 102, 7667;

b) T. F. Block, R. F. Fenske, J. Am. Chem. Soc. 1977, 99, 4321.

24. T. E. Taylor, M. B. Hall, J. Am. Chem. Soc. 1984, 106, 1576.

25. J. C. Green, M. L. H. Green, G. Parkin, Chem. Commun. 2012, 48, 11481.

26. J. Hartwig, Organotransition Metal Chemistry, University Science Books, California, 2010.

27. a) M. Fustier, X. F. Le Goff, P. Le Floch, N. Mézailles, J. Am. Chem. Soc. 2010, 132, 13108;b) D. P. Mills, L. Soutar, W. Lewis, A. J. Blake, S. T. Liddle, J. Am. Chem. Soc. 2010, 132, 14379; c) D. Mindiola, Nat. Chem. 2011, 3, 15.

28. D. J. Mindiola, G. L. Hillhouse, J. Am. Chem. Soc. 2002, 124, 9976.

29. M. Bröring, C. D. Brandt, S. Stellwag, Chem. Commun. 2003, 2344.

30. J. Campos, R. Peloso, E. Carmona, Angew. Chem. Int. Ed. 2012, 51, 8255.

31. R. Waterman, G. L. Hillhouse, J. Am. Chem. Soc. 2003, 125, 13350. 
32. N. D. Harrold, R Waterman, G. L. Hillhouse, T. R. Cundari, J. Am. Chem. Soc. 2009, 131, 12872 .

33. D. V. Gutsulyak, W. E. Piers, J. Borau-Garcia, M.Parvez, J. Am. Chem. Soc. 2013, $135,11776$.

34. C.-C. Liu, Q.-L. Liu, Z.-Y. Wu, Y.-C. Chen, H.-J. Xie, Q.-F. Lei, W.-J. Fang, J. Mol. Model. 2015, 21, 242.

35. V. M. Iluc, G. L. Hillhouse, J. Am. Chem. Soc. 2014, 136, 6479.

36. S. A. Künzi, J. M. Sarria Toro, T. den Hartog, P. Chen, Angew. Chem. Int. Ed. 2015, $54,10670$.

37. N, D. Staudaher, A. M. Arif, J. Louie, J. Am. Chem. Soc. 2016, 138, 14083.

38. W. H. Meyer, M. Deetlefs, M. Pohlmann, R. Scholz, M. W. Esterhuysen, G. R. Julius, H. G. Raubenheimer, Dalton Trans. 2004, 413.

39. W. Weng, C.-H. Chen, B. M. Foxman, O. V. Ozerov, Organometallics 2007, 26, 3315.

40. B. J. Barrett, V. M. Iluc, Organometallics 2017, 36, 730.

41. C. C. Comanescu, V. M. Iluc, Organometallics 2014, 33, 6059.

42. P. Cui, C. C. Comanescu, V. M. Iluc, Chem. Commun. 2015, 51, 6206.

43. C. Comanescu, V. M. Iluc, Organometallics 2015, 34, 4684.

44. C. C. Comanescu, V. M. Iluc, Chem. Commun. 2016, 52, 9048.

45. C. C. Comanescu, M. Vyushkova, M. Iluc, Chem. Sci. 2015, 6, 4570.

46. P. Cui, V. Iluc, Chem. Sci. 2015, 6, 7343.

47. P, Cui, M. R. Hoffbauer, M Vyushkova, V. M. Iluc, Chem. Sci. 2016, 7, 4444.

48. J. Campos, L. Ortega-Moreno, S. Conejero, R. Peloso, J. López-Serrano, C. Maya, E. Carmona, Chem. Eur. J. 2015, 21, 8883.

49. A. F. Heyduk, J. A. Labinger, J. E. Bercaw, J. Am. Chem. Soc. 2003, 125, 6366.

50. K. D. Lavoie, B. E. Frauhiger, P. S. White, J. L. Templeton, J. Organomet. Chem. 2015, 793, 182.

51. a) M. Lautens, W. Klute, W. Tam, Chem. Rev. 1996, 96, 49; b) I. Ojima, M. Tzamarioudaki, Z. Li, R. J. Donovan, Chem. Rev. 1996, 96, 635; c) H. W. Frühauf, Chem. Rev. 1997, 97, 523; d) D.-J. Huang, D. K. Rayabarapu, L.-P. Li, T. Sambaiah, C.-H. Cheng, Chem. Eur. J. 2000, 6, 3706; e) T.-Y. Hsiao, K. C. Santhosh, K.-F. Liou, C.-H. Cheng, J. Am. Chem. Soc. 1998, 120, 12232.

52. B. F. Straub, P. Hofmann, Angew. Chem. Int. Ed. 2001, 40, 1288. 
53. A. Caballero, E. Despagnet-Ayoub, M. M. Díaz-Requejo, A. Díaz-Rodríguez, M. E. González-Núñez, R. Mello, B. K. Muñoz, W.-S. Ojo, G. Asensio, M. Etienne, P. J. Pérez, Science 2011, 332, 835.

54. M. W. Hussong, W. T. Hoffmeister, F. Rominger, B. F. Straub, Angew. Chem. Int. Ed. 2015, 54, 10331.

55. G. Seidel, A. Fürstner, Angew. Chem. Int. Ed. 2014, 53, 4807.

56. R. J. Harris, R. A. Widenhoefer, Angew. Chem. Int. Ed. 2014, 53, 9369.

57. M. Joost, L. Estévez, S. Mallet-Ladeira, K. Miqueu, A. Amgoune, D. Bourissou, Angew. Chem. Int. Ed. 2014, 53, 14512.

58. M. W. Hussong, F. Rominger, P. Krämer, B. F. Straub, Angew. Chem. Int. Ed. 2014, $53,9372$.

59. E. Tudela, J. González, R. Vicente, J. Santamaría, M. A. Rodríguez, A. Ballesteros, Angew. Chem. Int. Ed. 2014, 53, 12097.

60. a) P. Hofmann, I. V. Shishkov, F. Rominger, Inorg. Chem. 2008, 47, 11775; b) I. V. Shishkov, F. Rominger, P. Hofmann, Organometallics 2009, 28, 1049.

61. R. S. Macomber, A complete introduction to Modern NMR Spectroscopy, Wiley: New York, 1998.

62. H. A. Bent, Chem. Rev. 1961, 61, 275.

63. X. Dai, T. H. Warren, J. Am. Chem. Soc. 2004, 126, 10085.

64. Y. M. Badiei, T. H. Warren, J. Organomet. Chem. 2005, 690, 5989.

65. N. P. Mankad, J. C. Peters, Chem. Commun. 2008, 1061.

66. J. Wang, X. Cao, S. Lv, C. Zhang, S. Xu, M. Shi1, J. Zhang, Nat. Commun. 8, 14625.

67. a) A. Fedorov, M.-E. Moret, P. Chen, J. Am. Chem. Soc. 2008, 130 ,8880; b) A. Fedorov, P. Chen, Organometallics 2009, 28, 1278; c) L. Batiste, A. Fedorov, P. Chen, Chem. Commun. 2010, 46, 3899; d) A. Fedorov, L. Batiste, A. Bach, D. M. Birney, P.Chen, J. Am. Chem. Soc. 2011, 133, 12162; e) D. H. Ringger, P.Chen, Angew. Chem. Int. Ed. 2013, 52, 46869; f) D. H. Ringger, I. J. Kobylianskii, D. Serra, P. Chen, Chem. Eur.J. 2014, 20, 14270; g) L. Batiste, P. Chen, J. Am. Chem. Soc. 2014, 136, 9296.

68. C. A. Swift, S. Gronert, Organometallics 2014, 33, 7135.

69. a) D. Benitez, N. D. Shapiro, E. Tkatchouk, Y. Wang, W. A. Goddard, F. D. Toste, Nat. Chem. 2009, 1, 482.; b) Y. Wang, M. E. Muratore, A. M. Echavarren, Chem. Eur. J. 2015, 21, 7332. 
70. C. Werlé, R. Goddard, A. Fürstner, Angew. Chem. Int. Ed. 2015, 54, 15452 .

71. Z. Lu, W. M. Jones, W. R. Winchester, Organometallics 1993, 12, 1344. 